\title{
Decision support in surgical management of ischemic cardiomyopathy
}

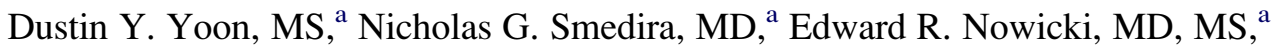

Katherine J. Hoercher, RN, ${ }^{\mathrm{a}}$ Jeevanantham Rajeswaran, MSc, ${ }^{\mathrm{b}}$ Eugene H. Blackstone, MD, ${ }^{\mathrm{a}, \mathrm{b}}$ and

Bruce W. Lytle, MD ${ }^{\mathrm{a}}$

Objectives: The surgical approach to ischemic cardiomyopathy maximizing survival remains a dilemma, with decisions complicated by secondary mitral regurgitation, ventricular remodeling, and heart failure. As a component of decision support, we sought to develop prediction models for comparing survival after coronary artery bypass grafting alone, coronary artery bypass grafting plus mitral valve anuloplasty, coronary artery bypass grafting plus surgical ventricular restoration, and listing for cardiac transplantation.

Methods: From 1997 to 2007, 1468 patients with ischemic cardiomyopathy (ejection fraction <30\%) underwent coronary artery bypass grafting alone $(\mathrm{n}=386)$, coronary artery bypass grafting plus mitral valve anuloplasty $(\mathrm{n}$ $=212$ ), coronary artery bypass grafting plus surgical ventricular restoration $(n=360)$, or listing for cardiac transplantation $(\mathrm{n}=510)$. Mean follow-up was $3.8 \pm 2.8$ years, with 5577 patient-years of data available for analysis. Risk factors were identified for early and late mortality by using $80 \%$ training and $20 \%$ validation sets. Outcomes were calculated for each applicable strategy to identify which maximized predicted 5-year survival. Models were programmed as a strategic decision-support tool.

Results: One-, 5-, and 9-year survival were as follows, respectively: coronary artery bypass grafting, 92\%, 72\%, and $53 \%$; coronary artery bypass grafting plus mitral valve anuloplasty, $88 \%, 57 \%$, and $34 \%$; coronary artery bypass grafting plus surgical ventricular restoration, $94 \%, 76 \%$, and $55 \%$; and listing for cardiac transplantation, $79 \%, 66 \%$, and 54\%. Risk factors included older age, higher New York Heart Association class, lower ejection fraction, longer interval from myocardial infarction to operation, and numerous comorbidities. Predicted and observed survivals in validation groups were similar $(P>.1)$. Patient-specific simultaneous solutions of applicable models revealed therapy potentially providing maximum survival benefit. Coronary artery bypass grafting alone and listing for cardiac transplantation often maximized 5-year survival; only $15 \%$ of patients undergoing coronary artery bypass grafting plus mitral valve anuloplasty were predicted to fare best with this therapy.

Conclusion: Validated prediction models can aid surgeons in recommending personalized treatment plans that maximize short- and long-term survival for ischemic cardiomyopathy. (J Thorac Cardiovasc Surg 2010;139:283-293)

Supplemental material is available online.

With multiple surgical therapies for ischemic cardiomyopathy, recommending one that is both applicable and maxi-

\footnotetext{
From the Department of Thoracic and Cardiovascular Surgery, ${ }^{a}$ Heart and Vascular Institute, and the Department of Quantitative Health Sciences, ${ }^{b}$ Research Institute, Cleveland Clinic, Cleveland, Ohio.

Disclosures: None.

Read at the Eighty-eighth Annual Meeting of The American Association for Thoracic Surgery, San Diego, Calif, May 10-14, 2008.

D. Y. Yoon is supported in part by the American Association for Thoracic Surgery Summer Intern Scholarship for Medical Students. E. H. Blackstone is supported in part by the Kenneth Gee and Paula Shaw, PhD, Chair in Heart Research.

Received for publication May 1, 2008; revisions received July 20, 2009; accepted for publication Aug 14, 2009.

Address for reprints: Nicholas G. Smedira, MD, Department of Thoracic and Cardiovascular Surgery, Cleveland Clinic, 9500 Euclid Ave/Mail Stop J4-1, Cleveland, OH 44195 (E-mail: smedirn@ccf.org).

$0022-5223 / \$ 36.00$

Copyright (c) 2010 by The American Association for Thoracic Surgery

doi:10.1016/j.jtcvs.2009.08.055
}

mizes survival for a given patient often remains a dilemma. These therapies include coronary artery bypass grafting $(\mathrm{CABG})$ alone when there is viable, perhaps hibernating myocardium; CABG with mitral valve (MV) anuloplasty (MVA) when severe chronic secondary mitral regurgitation (MR) accompanies ischemic disease; CABG with surgical ventricular restoration (SVR; the Dor procedure ${ }^{1}$ ) when the anterior myocardium is akinetic or dyskinetic; and listing for cardiac transplantation (LCTx) when alternative interventions might not ameliorate the circumstances. What is needed is a personalized strategic algorithm and decision aid to assist surgeons in recommending a therapy and patients in making an informed decision.

The purposes of this study were to (1) develop and validate comparative prediction models of survival after these 4 surgical interventions, (2) calculate how many patients are predicted to experience better survival after an applicable therapy other than the one received, and (3) transform these models into a computer-based strategic decision aid for facilitating personalized decision making. 


\author{
Abbreviations and Acronyms \\ $\mathrm{CABG}=$ coronary artery bypass grafting \\ LCTx $=$ listing for cardiac transplantation \\ $\mathrm{MR}=$ mitral regurgitation \\ MV = mitral valve \\ MVA $=$ mitral valve anuloplasty \\ NYHA $=$ New York Heart Association \\ SVR $=$ surgical ventricular restoration
}

\section{MATERIALS AND METHODS \\ Patients}

From 1997 to 2007, 1468 patients were surgically treated for ischemic cardiomyopathy at Cleveland Clinic. Ischemic cardiomyopathy was defined as severe left ventricular systolic dysfunction with a measured or estimated ejection fraction of less than $30 \%$, as determined by ventriculographic or echocardiographic analysis. Of these patients, 386 underwent CABG alone, 212 CABG+MVA, 360 CABG + SVR, and 510 LCTx. All patients not listed for transplantation and $88 \%$ of the LCTx group had a documented remote (>30 days) myocardial infarction. Most patients had multisystem coronary artery disease and multiple noncardiac comorbidities (Table 1).

\section{Data}

Clinical, angiographic, and electrocardiographic variables and details of the surgical procedures were obtained from prospective clinical cardiovascular information registries maintained concurrently with patient care. All data were approved for use in research by the institutional review board, with patient consent waived.

Myocardial viability, an important factor in identifying applicable therapies, was assessed by using delayed hyperenhancement cardiac magnetic resonance imaging after administering a gadolinium-based contrast agent in 153 patients, dobutamine echocardiographic analysis in 111 patients, fluorodeoxyglucose positron emission tomographic analysis in 15 patients, 99-mTc-single photon emission computed tomographic analysis in 11 patients, and thallium stress studies in 7 patients (Table E1). Availability of data was strongly associated with therapy received, with the majority of these tests performed in the $\mathrm{CABG}+\mathrm{SVR}$ group. Thus, data were insufficient from these multiple modalities to formulate a single viability score and model its influence on survival.

\section{End Point}

The primary end point for developing the decision aid was all-cause time-related mortality, including in-hospital mortality after surgical procedures and interim deaths while awaiting transplantation (Table E2). Patients were followed routinely with consent. This active follow-up was supplemented with passive data using the Social Security Death Index, ${ }^{2,3}$ with a common closing date of February 16, 2007. Mean duration of follow-up was $3.8 \pm 2.8$ years, and 5577 patient-years of follow-up were available for analysis. Among survivors, $25 \%$ were followed for more than 6.8 years, and $10 \%$ were followed for more than 8.7 years. Survival estimates were considered reliable to 9 years.

\section{Data Analysis}

Brief summary. Using a random $80 \%$ training dataset, multivariable analysis of mortality was performed for each therapy (therapy-specific analysis) based solely on preoperative variables (Appendix 1). ${ }^{4-6}$ Therapy-specific analyses were performed because each exhibited a different temporal pattern of risk of death (hazard function, Figure E1) because some risk factors were more prominently associated with mortality in one group and less so in another. Having developed therapy-specific risk-factor models, all variables appearing in any of the 4 models were incorporated into 4 final training models, all with a common set of predictors, regardless of statistical significance (semisaturated models).

Because the objective of the study was not to compare survival of groups of similar patients but rather to predict survival for an individual's personal characteristics and condition, we deliberately did not adjust the prediction models for selection factors (eg, by using propensity scores). ${ }^{7}$

For validation, the 4 training models were used to predict survival of each patient in the $20 \%$ hold-out data set. Two validation criteria were used: (1) comparing the number of observed deaths versus predicted deaths ${ }^{8}$ and (2) comparing observed versus predicted survival. ${ }^{9}$ Thereafter, final semisaturated decision-support models for each therapy were formulated by using all the data (see the online Methods section for details of model development and validation).

Survival comparison. To investigate whether the therapy received maximized survival, we predicted 5-year survival after each therapy for each patient. However, not all therapies are applicable to a given patient, and therefore general clinical criteria were used to select by automated means the comparisons deemed applicable. A major factor used clinically to identify applicable therapies is the presence of ischemic symptoms (angina) and the presence of viable myocardium in territories with diseased but bypassable coronary arteries (Figure 1). Because of the paucity of viability data, with the data available, we were able to incompletely assess the applicability of CABG. For patients without such studies, we used the American College of Cardiology/American Heart Association guidelines for applicability of CABG based on angina and coronary artery disease. ${ }^{10}$ Thus, we considered $1082(74 \%)$ patients to be eligible for CABG alone, $598(41 \%)$ for CABG+MVA when $3+44+$ MR was present, $742(50 \%)$ for CABG + SVR when anterior wall akinesia or dyskinesia was present and left ventricular end-diastolic diameter was greater than $6.0 \mathrm{~cm}$, and 671 $(46 \%)$ for transplantation when age was less than 70 years, New York Heart Association (NYHA) functional class was III/IV, and creatinine level was less than $1.7 \mathrm{mg} \cdot \mathrm{dL}^{-1}$.

Presentation. Continuous variables are summarized as means \pm standard deviations and as 15 th, 50th (median), and 85th percentiles when values were skewed, which is consistent with \pm 1 standard deviation. Comparisons used the Kruskal-Wallis test. Categorical data are summarized by frequencies and percentages. Comparisons used the $\chi^{2}$ test. Uncertainty is expressed by $68 \%$ confidence limits, which is consistent with \pm 1 standard error. All analyses were performed with SAS statistical software (SAS version 9.1; SAS Institute, Inc, Cary, NC).

\section{Decision-support Tool}

We developed a java-based user interface that used these hazard-based models to predict individual patient survival curves for applicable therapies based on PROC HAZARD, which is described at http://www. clevelandclinic.org/heartcenter/hazard. This application accepts individual patient characteristics for each variable in the models as inputs, allowing surgeons to compare the resulting survival curves predicted for each applicable therapy or investigate how individual characteristics affect prognosis.

\section{RESULTS}

\section{Survival and Risk-factor Models}

After CABG alone, unadjusted survival at 1,3,5, and 9 years was $92 \%, 82 \%, 72 \%$, and $53 \%$, respectively (Figure 2). Risk factors included NYHA functional class III/IV for early death and multiple noncardiac comorbidities for late death (Table 2). After CABG + MVA, unadjusted survival at $1,3,5$, and 9 years was $88 \%, 72 \%, 57 \%$, and 
TABLE 1. Patient characteristics by surgical therapy

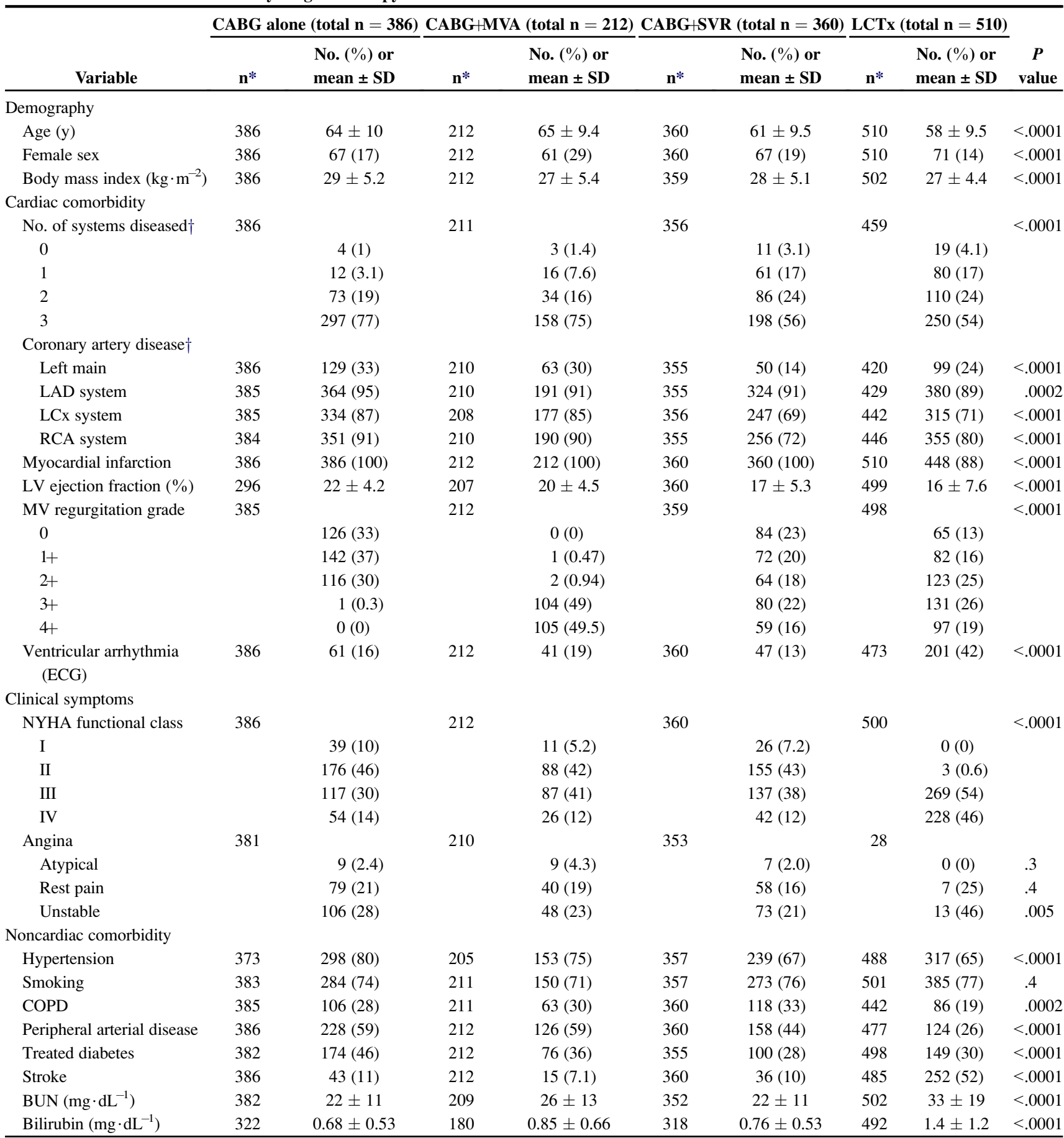

$C A B G$, Coronary artery bypass grafting; $M V A$, mitral valve anuloplasty; $S V R$, surgical ventricular restoration; $L C T x$, listing for cardiac transplantation; $S D$, standard deviation; $L A D$, left anterior descending coronary artery; $L C x$, left circumflex coronary artery; $R C A$, right coronary artery; $L V$, left ventricular; $M V$, mitral valve; $E C G$, electrocardiogram; $N Y H A$, New York Heart Association; $C O P D$, chronic obstructive pulmonary disease; $B U N$, blood urea nitrogen. *Number of patients with data available. $\dagger$ Fifty percent or greater stenosis.

$34 \%$, respectively. Risk factors included lower ejection fraction for early death and longer interval from myocardial infarction to operation, complete heart block, left circumflex coronary artery stenosis, and noncardiac comorbidities for late death (Table 2). After CABG+SVR, unadjusted survival at $1,3,5$, and 9 years was $94 \%, 86 \%, 76 \%$, and $55 \%$, respectively. Risk factors included lower ejection fraction and higher Canadian Angina Class for early death and both cardiac and noncardiac comorbidities for late death (Table 2). After LCTx, unadjusted survival at 1,3,5, and 9 years 


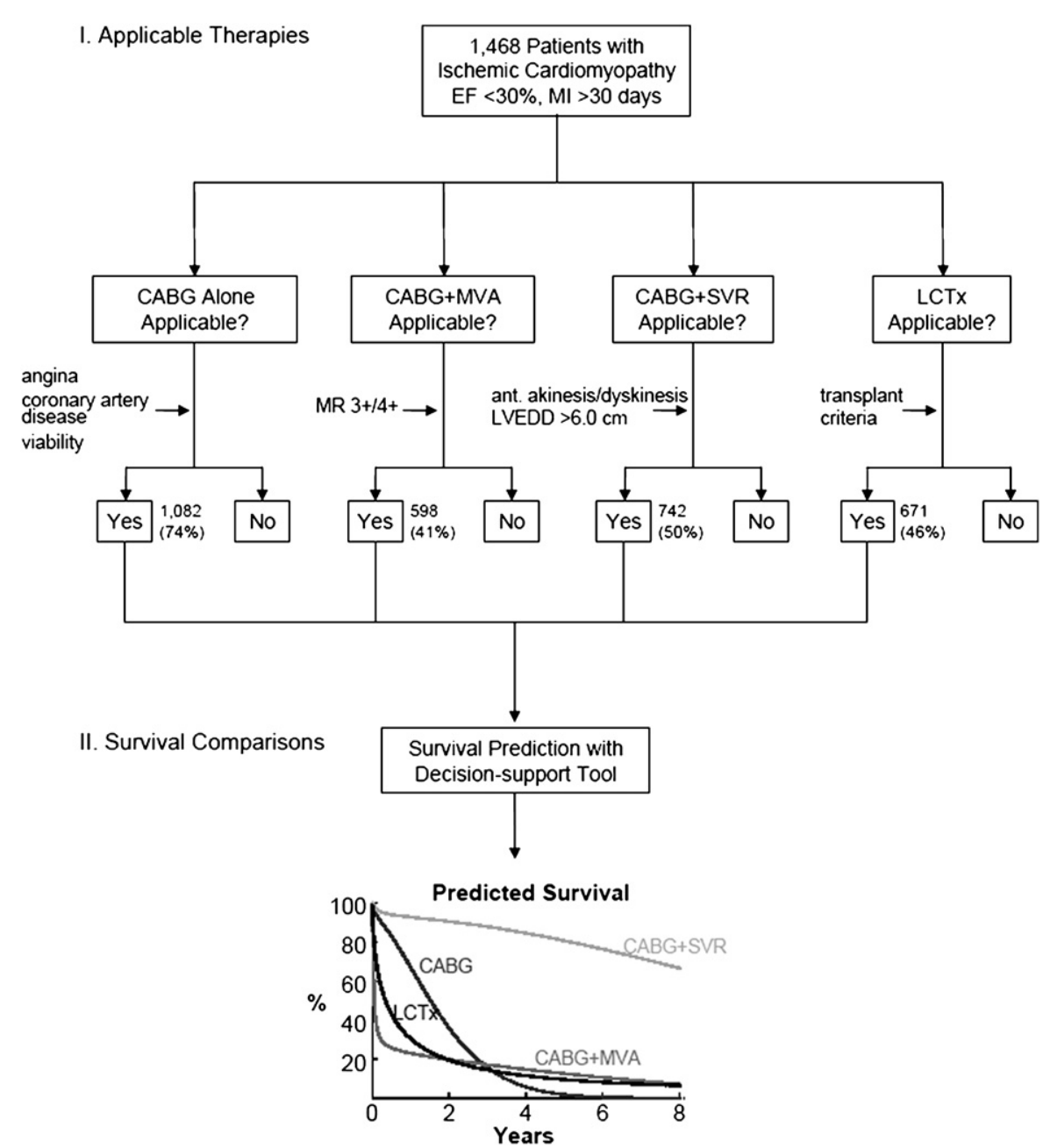

FIGURE 1. Decision-support schema. I, Therapies applicable for ischemic cardiomyopathy. II, Survival comparisons of only applicable surgical therapies in the decision-support model. $E F$, Ejection fraction; $M I$, myocardial infarction; $C A B G$, coronary artery bypass grafting; $M V A$, mitral valve anuloplasty; SVR, surgical ventricular restoration; $L C T x$, listing for cardiac transplantation; $M R$, mitral regurgitation; $L V E D D$, left ventricular end-diastolic diameter.

was $79 \%, 72 \%, 66 \%$, and $54 \%$, respectively. Risk factors included older age, ventricular arrhythmia, and 3-system coronary disease for early death and longer interval from myocardial infarction to listing and both cardiac and noncardiac comorbidities for late death (Table 2). Of 510 patients in the LCTx group, 94 died awaiting transplantation, all of whom were included in the analysis; 54 were delisted because of recovery or destination therapy; and 348 underwent transplantation.

Among the risk-factor models for each of the 4 therapies, 24 unique factors (Table 2) appeared, all of which were incorporated into our final decision-support models (Table E3).

\section{Model Validation}

The number of deaths predicted by each training model corresponded well $(P>.1)$ with the observed number of deaths in the $20 \%$ holdout sample (Table E4). Observed sur- vival estimates after each therapy were well within confidence limits of predicted survival, and the Brier score was nearly always less than 0.25 , both of which are indicative of excellent prediction (Figure E2).

\section{Survival Comparisons}

Among the 1468 patients, only 1 therapy received was deemed applicable in $420(29 \%), 2$ in $581(40 \%), 3$ in 357 $(24 \%)$, and all 4 in $110(7.5 \%)$. Of patients for whom more than 1 therapy was considered applicable, $750(51 \%)$ were predicted to have better 5 -year survival with a therapy other than the one received (Figure 3), although the difference in survival ranged from trivial to large ( Figure E3). This was particularly true of CABG + MVA, for which survival was predicted to be better with CABG alone in $133(63 \%)$ patients for whom alternative therapies were considered appropriate. The highest concordance with treatment received was $\mathrm{CABG}$ alone $(72 \%)$ and the lowest was CABG+MVA (15\%). 


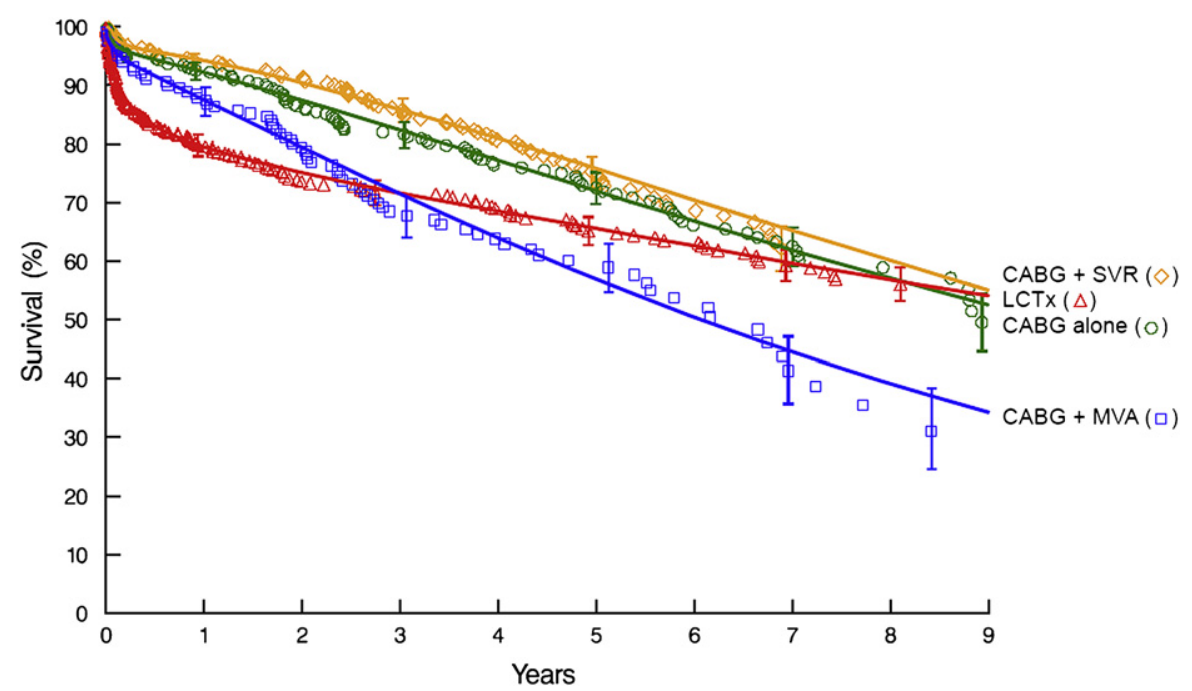

FIGURE 2. Time-related mortality after surgical therapies for ischemic cardiomyopathy. Each symbol represents a death positioned on a vertical axis by using a Kaplan-Meier estimator, and vertical bars represent $68 \%$ confidence limits equivalent to \pm 1 standard error. Solid lines are parametric survival estimates. $C A B G$, Coronary artery bypass grafting; $S V R$, surgical ventricular restoration; $L C T x$, listing for cardiac transplantation; $M V A$, mitral valve anuloplasty.

\section{Strategic Decision Aid and Case Presentation}

Using the decision-support tool, patient-specific simultaneous solutions for time-related survival after those therapies considered appropriate revealed procedures that potentially could have maximized survival. Consider a 53year-old male patient with ischemic cardiomyopathy and an anterior infarction 2 years ago with akinetic but viable myocardium; an ejection fraction of $25 \%$; a left ventricular end-diastolic diameter of $6.5 \mathrm{~cm}$; NYHA functional class IV based on heart failure symptoms; MR grade 3+; 3-system coronary disease; and multiple noncardiac comorbidities. Before survival is calculated, each therapy is evaluated for applicability. For example, myocardial viability was assessed and found adequate, and his severely stenotic coronary arteries were considered suitable for CABG. His moderately severe MR made CABG+MVA applicable, and his greater than $6.0-\mathrm{cm}$ left ventricular end-diastolic diameter made $\mathrm{CABG}+\mathrm{SVR}$ applicable. He was evaluated for heart transplantation and found to have no contraindications. Thus, for illustration, all 4 therapies were considered applicable for this unusual combination of risk factors. As shown in the Figure 4, $A$, scenario, all therapies were predicted to yield different long-term prognoses, with LCTx having the best survival and CABG+MVA the worst. A screenshot of the strategic decision aid for this patient is shown in Figure 5.

We can then explore the consequences of altering the patient's clinical profile, as detailed in Table E5. Five years later, this same patient has an anterior aneurysm, left main disease, and severe renal disease. His survival is predicted to be even worse with CABG + MVA (Figure 4, $B$, scenario) but better with $\mathrm{CABG}+\mathrm{SVR}$; CABG alone and LCTx are no longer applicable because of the absence of viable myocardium and se- vere renal disease, respectively. If the patient does not have MR, has viable myocardium without dyskinesis/akinesis, and has severe 3 -system coronary disease, then $\mathrm{CABG}+\mathrm{SVR}$ and $\mathrm{CABG}+\mathrm{MVA}$ are no longer applicable, and $\mathrm{CABG}$ alone is predicted to result in better survival than LCTx (Figure 4, $C$, scenario). If the patient has the unusual combination of low ejection fraction $(15 \%)$, MR grade $4+$, and multiple cardiac and noncardiac comorbidities, $\mathrm{CABG}+\mathrm{MVA}$ is predicted to maximize survival (Figure 4, $D$, scenario).

\section{DISCUSSION \\ Principal Findings}

Our predictive models, incorporating 24 routinely assessed clinical and cardiac structural variables, reliably demonstrate that each surgical therapy for ischemic cardiomyopathy has a unique short- and long-term survival pattern that is predictable but highly variable from patient to patient. In general, CABG+MVA was associated with the lowest 5-year survival, and these patients in particular might benefit from an alternative intervention. CABG alone, CABG+SVR, and LCTx often had comparable long-term outcomes, but CABG requires myocardial viability and bypassable coronary arteries. It appears that more patients with viability might benefit from a simple and safe procedure (CABG alone) and that patients with more advanced NYHA functional class symptoms of heart failure would have improved long-term survival with LCTx.

\section{Surgical Decision for Ischemic Cardiomyopathy}

For more than 15 years, aggressive surgical treatment of advanced ischemic cardiomyopathy has been advocated as an alternative to transplantation. This study focused on the 
TABLE 2. Incremental risk factors for death by surgical therapy

\begin{tabular}{|c|c|c|c|}
\hline Factor & $\begin{array}{l}\text { Coefficient } \\
\quad \pm \text { SD }\end{array}$ & $\begin{array}{c}P \\
\text { value }\end{array}$ & $\begin{array}{c}\text { Reliability } \\
(\%) *\end{array}$ \\
\hline \multicolumn{4}{|l|}{ CABG alone } \\
\hline \multicolumn{4}{|l|}{ Early hazard phase } \\
\hline NYHA functional class III/IV & $1.4 \pm 0.58$ & .02 & 50 \\
\hline Stroke & $1.5 \pm 0.50$ & .004 & 69 \\
\hline \multicolumn{4}{|l|}{ Late hazard phase } \\
\hline Older age $\dagger$ & $0.52 \pm 0.16$ & .002 & 71 \\
\hline Treated diabetes & $0.90 \pm 0.24$ & .0001 & 64 \\
\hline COPD & $1.3 \pm 0.25$ & $<.0001$ & 94 \\
\hline Popliteal disease & $0.73 \pm 0.26$ & .006 & 52 \\
\hline Higher cholesterol $\ddagger$ & $-3.5 \pm 1.1$ & .002 & 76 \\
\hline \multicolumn{4}{|l|}{ CABG+MVA } \\
\hline \multicolumn{4}{|l|}{ Early hazard phase } \\
\hline Lower LV ejection fraction $\S$ & $-3.2 \pm 1.5$ & .03 & 65 \\
\hline \multicolumn{4}{|l|}{ Late hazard phase } \\
\hline $\begin{array}{l}\text { Longer interval from } \\
\text { MI to operation } \|\end{array}$ & $0.019 \pm 0.0079$ & .02 & 58 \\
\hline Complete heart block & $0.800 \pm 0.32$ & .01 & 57 \\
\hline LCx disease ( $\geq 70 \%$ stenosis $)$ & $0.69 \pm 0.30$ & .02 & 71 \\
\hline Insulin-treated diabetes & $0.67 \pm 0.31$ & .03 & 65 \\
\hline Renal disease & $1.1 \pm 0.32$ & .0008 & 98 \\
\hline Higher BUN & $1.1 \pm 0.32$ & .0009 & 98 \\
\hline \multicolumn{4}{|l|}{ CABG+SVR } \\
\hline \multicolumn{4}{|l|}{ Early hazard phase } \\
\hline Lower LV ejection fraction $\S$ & $-1.8 \pm 0.800$ & .02 & 60 \\
\hline Higher Canadian Angina Class & $0.77 \pm 0.36$ & .03 & 78 \\
\hline \multicolumn{4}{|l|}{ Late hazard phase } \\
\hline Lower LV ejection fraction\# & $-0.76 \pm 0.28$ & .008 & 77 \\
\hline Atrial fibrillation & $1.5 \pm 0.45$ & .001 & 62 \\
\hline Left main disease (any stenosis) & $0.51 \pm 0.27$ & .05 & 90 \\
\hline RCA disease ( $\geq 50 \%$ stenosis $)$ & $0.705 \pm 0.32$ & .03 & 90 \\
\hline Aortic valve regurgitation & $0.87 \pm 0.305$ & .004 & 57 \\
\hline Higher BUNף & $1.00 \pm 0.29$ & .0005 & 62 \\
\hline Lower hematocrit** & $-4.0 \pm 0.91$ & $<.0001$ & 77 \\
\hline \multicolumn{4}{|l|}{ Heart transplantation-at listing } \\
\hline \multicolumn{4}{|l|}{ Early hazard phase } \\
\hline Older age $\dagger \dagger$ & $1.6 \pm 0.63$ & .01 & 54 \\
\hline Ventricular arrhythmia & $0.39 \pm 0.200$ & .05 & 62 \\
\hline Three-system coronary disease $\ddagger \ddagger$ & $0.69 \pm 0.21$ & .001 & 91 \\
\hline Higher BUN $\S \S$ & $0.060 \pm 0.012$ & $<.0001$ & 99 \\
\hline Higher bilirubin & $0.26 \pm 0.062$ & $<.0001$ & 79 \\
\hline \multicolumn{4}{|l|}{ Late hazard phase } \\
\hline $\begin{array}{l}\text { Longer interval from } \\
\text { MI to listing }\|\|\end{array}$ & $0.044 \pm 0.018$ & .01 & 75 \\
\hline Insulin-treated diabetes & $1.2 \pm 0.55$ & .02 & 70 \\
\hline Aortic valve regurgitation & $1.5 \pm 0.55$ & .007 & 83 \\
\hline Ventricular arrhythmia & $1.2 \pm 0.62$ & .05 & 70 \\
\hline Peripheral arterial disease & $1.5 \pm 0.59$ & .01 & 63 \\
\hline
\end{tabular}

$S D$, Standard deviation; $C A B G$, coronary artery bypass grafting; $N Y H A$, New York Heart Association; $C O P D$, chronic obstructive pulmonary disease; $M V A$, mitral valve anuloplasty; $L V$, left ventricular; $M I$, myocardial infarction; $L C x$, left circumflex coronary artery; $B U N$, blood urea nitrogen; $S V R$, surgical ventricular restoration; $R C A$, right coronary artery. $*$ Percentage of times variable appeared in 1000 bootstrap analyses. $\dagger \operatorname{Exp}($ age/50), exponential transformation. $\ddagger(100 /$ cholesterol level), inverse transformation. $\S \mathrm{Ln}(\mathrm{LV}$ ejection fraction [\%]), logarithmic transformation. $\|($ Years from MI to operation/3) ${ }^{2}$, squared transformation. $\uparrow \operatorname{Ln}(B U N)$, logarithmic transformation. \#(LV ejection fraction $[\%] / 20)^{2}$, squared transformation. ** $\operatorname{Ln}$ (hematocrit), logarithmic transformation. $\dagger \dagger \operatorname{Ln}($ age), logarithmic transformation. $\ddagger \ddagger$ Fifty percent or greater stenosis in all LADs, LCxs, and RCAs. $\S \S(\mathrm{BUN} / 20)^{2}$, squared transformation. || ||(Interval from MI to listing [years] $/ 4)^{2}$, squared transformation.
4 most commonly recommended of these for which longterm survival data were available. Each has specific indications, but for a given patient, more than 1 of these might be deemed appropriate.

MV intervention. The survival advantage of this surgical intervention has been challenged. Tolis and colleagues ${ }^{11}$ and Mihaljevic and colleagues ${ }^{12}$ found no long-term survival advantage to adding MV repair to CABG in patients with either moderate or severe ischemic $\mathrm{MR}$, and $\mathrm{Wu}$ and colleagues $^{13}$ demonstrated that medical therapy yielded similar survival to surgical intervention. Gorman and Gorman's ${ }^{14}$ commentary on the article by Tolis and colleagues ${ }^{11}$ accurately states that the effect of MV intervention on survival is minimal and prognosis is poor. Refining selection of therapies for these patients with moderate or severe ischemic MR is urgently needed. Our model using simple clinical variables suggests that in the presence of lower ejection fraction and heart failure symptoms, therapies other than CABG + MVA should be evaluated.

CABG alone and CABG + SVR. Most supporting evidence for direct revascularization in patients with reduced left ventricular function is derived from studies conducted in the 1970s and 1980s that predated modern surgical techniques, devices, and medical therapies. ${ }^{15}$ Subsequent information identified ischemic features less likely to respond to CABG alone. Poor target-vessel quality, ${ }^{16}$ large ventricular volume, ${ }^{17,18}$ and absence of myocardial viability ${ }^{19}$ were associated with worse survival, and our models show that after CABG alone, patients who had atrial fibrillation and chronic obstructive pulmonary disease experienced worse outcomes. Reducing ventricular size to improve function makes theoretical sense, ${ }^{20}$ but modeling data suggest the equal possibility of worsening ventricular diastolic function. ${ }^{21,22}$ The National Heart, Lung, and Blood Institute-funded Surgical Treatment for Ischemic Heart Failure trial showed that concomitant addition of SVR to CABG alone resulted in reduced left ventricular volume, but did not reduce deaths or hospitalizations for cardiac causes. ${ }^{23}$ Many of our simulations revealed similar survival outcomes with CABG alone or $\mathrm{CABG}+\mathrm{SVR}$. Subanalyses examining the relationships of ventricular volumes to outcomes and the role of medical therapy might elucidate these interactions. ${ }^{23}$

LCTx. Although survival after heart transplantation is good, there is considerable mortality while awaiting transplantation; $18 \%$ of our LCTx cohort died during this period. Selecting patients who will be best served by transplantation is difficult and becoming more so because 1-year survival of status 2 patients is now equivalent to that of patients receiving a transplant. ${ }^{24,25}$ Our results should be viewed cautiously because we did not incorporate all standard transplantation criteria into our simulation of the complex decision-making processes; specifically, most patients receiving alternative therapies would not have been listed as status 1A or 1B. Our models confirmed our clinical suspicion of which 


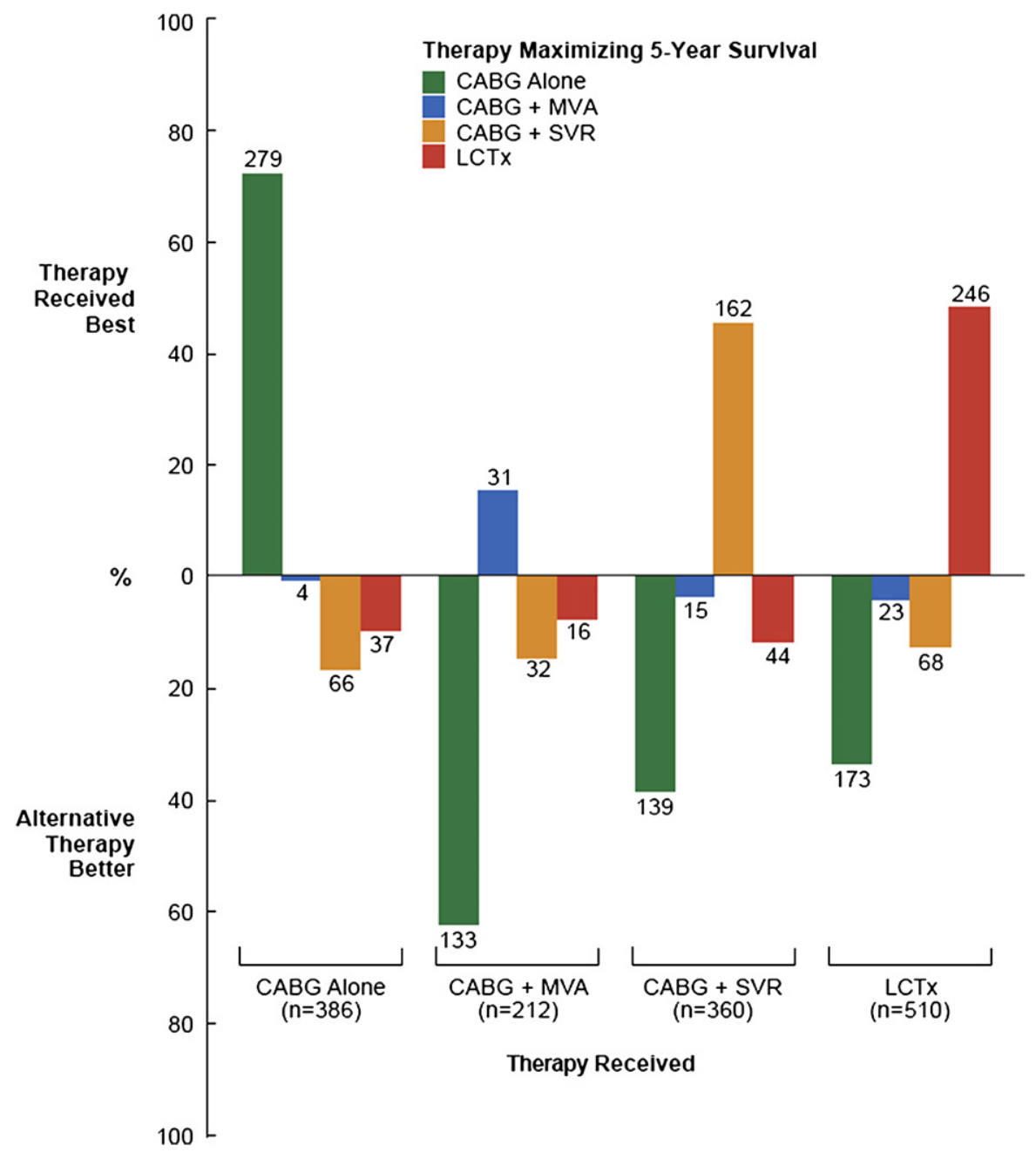

FIGURE 3. Percentage (and number of patients for each bar) of patients predicted to have the highest 5-year survival after therapy received (upward-pointing bars) and those of patients predicted to have better 5-year survival with an alternative therapy (downward-pointing bars) for each therapy received. $C A B G$, Coronary artery bypass grafting; $M V A$, mitral valve anuloplasty; $S V R$, surgical ventricular restoration; $L C T x$, listing for cardiac transplantation.

candidates might be better served by a nontransplantation alternative. In older patients with renal dysfunction and other heart failure symptoms, LCTx offered no survival advantage over $\mathrm{CABG}+\mathrm{MVA}$ or $\mathrm{CABG}$ alone.

\section{Decision Support}

Clinical decision making is a collaborative effort between clinician and patient. For the clinician, the type of decision support presented in this article tailors information on available therapeutic options to the patient in a manner that is understandable and unbiased. With decompensating patients who have a complex clinical makeup, it becomes difficult for the clinician to discern the therapy that maximizes survival and to recognize subtle changes that can have longterm ramifications. The tool presented can be used during consultation to illustrate the tradeoffs of specific therapies and provide a better medium for informed consent, allowing a better collaborative approach to decision making. It can be used to determine whether a patient is less likely to benefit from alternative treatments and to facilitate formulating risk-reduction strategies.

For the patient, decision making involves not only giving consent to a clinician's recommendation but also evaluating and appreciating the tradeoffs of short-term risk and longterm gain. Although survival is ultimate, a patient also needs to take into consideration effects of alternative therapies on quality of life. Increasingly, medical decisions are also being scrutinized on the basis of short- and long-term costs of care to society, often without considering the offsetting contributions these patients give back to society. ${ }^{26}$

Clinicians are becoming aware of the difficulty of assimilating the multitude of factors and their complex interplay in formulating therapeutic recommendations for their patients. Unknowingly, these recommendations are made with many biases, in which surgeons rely on past experience with similar cases. Practically, they often use simple heuristic rules 

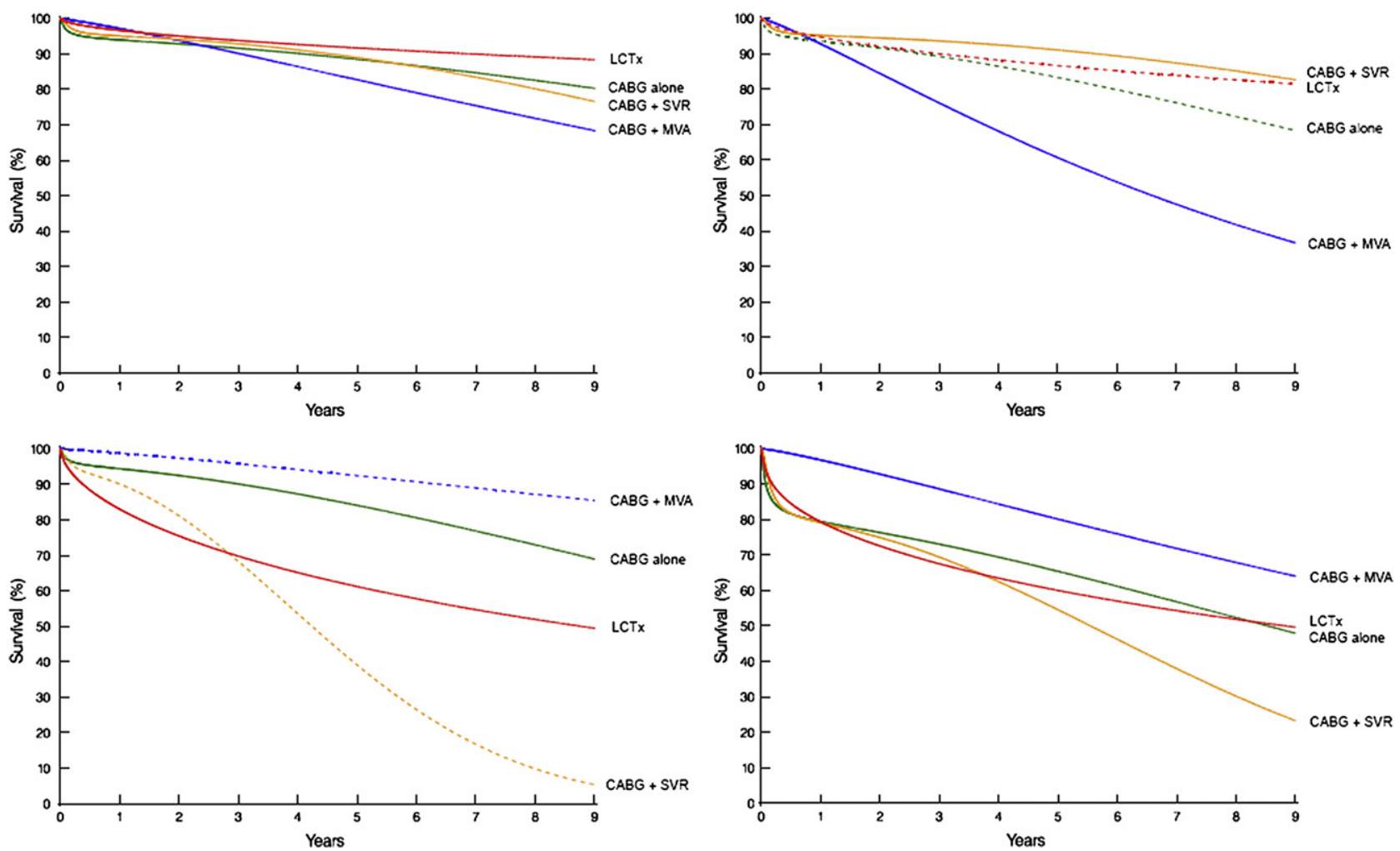

FIGURE 4. Survival predicted after each of 4 therapies for 4 different scenarios (see Table E5 for details). Top left, Scenario A; top right, scenario B; bottom left, scenario C; bottom right, scenario D. Dashed lines represent artificial survival curves for therapies not deemed applicable for the given patient's characteristics. $L C T x$, Listing for cardiac transplantation; $C A B G$, coronary artery bypass grafting; $S V R$, surgical ventricular restoration; $M V A$, mitral valve anuloplasty.

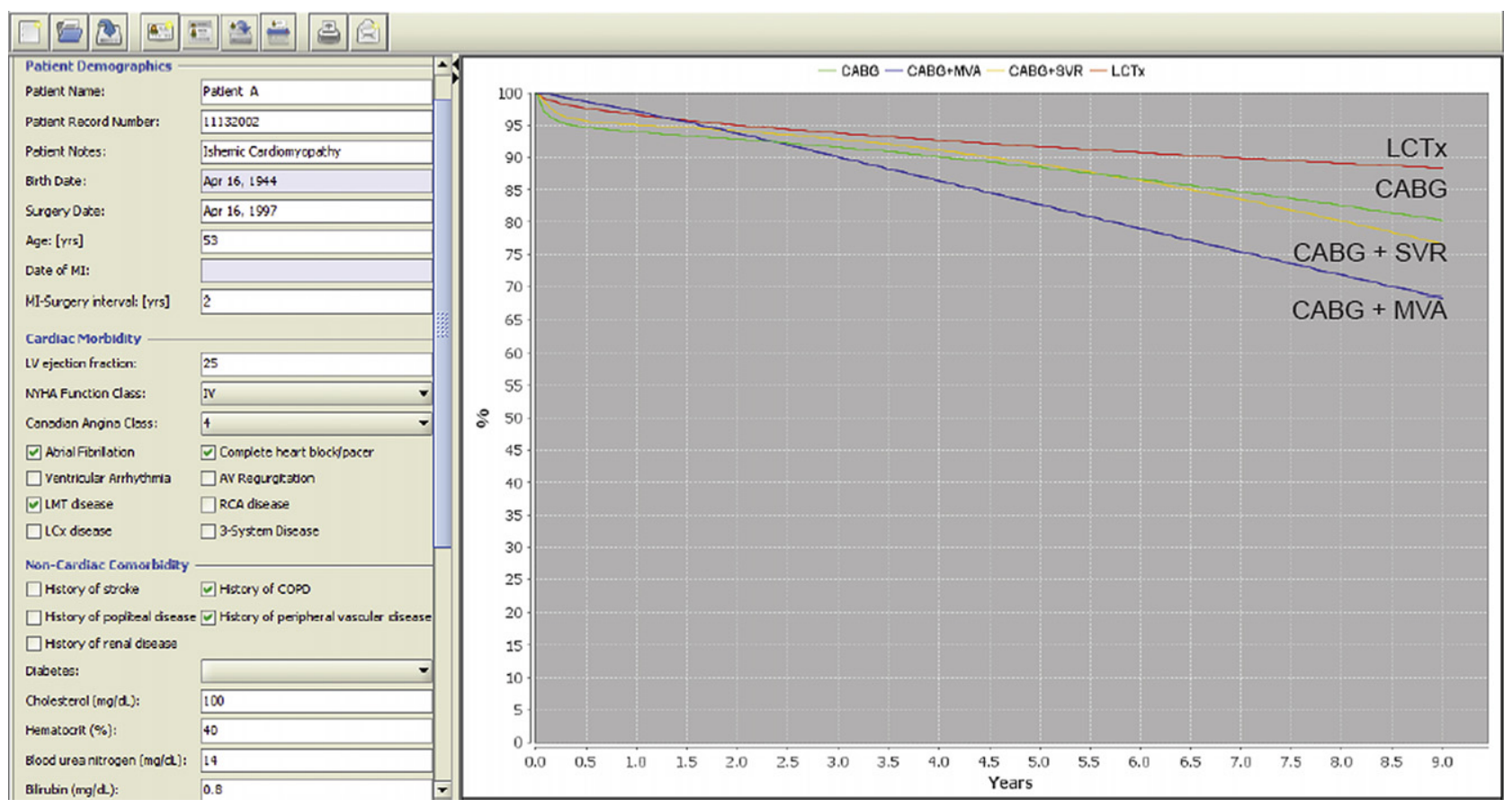

FIGURE 5. Java-based user interface for clinical strategic decision support. Results for scenario A in Figure 4 are shown. $C A B G$, Coronary artery bypass grafting; $M V A$, mitral valve anuloplasty; SVR, surgical ventricular restoration; $L C T x$, listing for cardiac transplantation. Used by permission of Cleveland Clinic. 
rather than continuous analysis to stratify patients. ${ }^{27,28}$ For example, a surgeon might recognize the risk of renal failure if the creatinine value is 1.5 times the baseline value, but will not differentiate it as a continuous variable. Cognitive capacity limitations in human subjects restrict detection of strong correlations when the number of variables exceeds $7 \pm 2$ items. ${ }^{29}$ Our model has been developed from more than 75 preoperative variables in addition to multiple transformations of each continuous variable, a difficult feat for a surgeon to fully assimilate. Impeding accurate recommendations further, individuals rely on fewer cues for decision making when information load is high or time constraints are present. ${ }^{30}$

Thus, clinicians increasingly rely on risk-assessment tools to guide therapies, including the EuroSCORE ${ }^{31}$ the Society of Thoracic Surgeons risk models, ${ }^{32}$ the Seattle Heart Failure Model, ${ }^{33}$ and the preoperative risk score for mortality after left ventricular assist device surgery. ${ }^{34}$ These and our "cognitive prosthesis" tool are not meant to replicate or replace surgeons' cognition through prediction models ${ }^{35}$ but rather to synergistically augment and extend their capabilities. $^{36}$

\section{Study Limitations}

This is a single-institution clinical study. Surgical procedures analyzed were performed over many years, during which all clinical variables were not uniformly collected. We did not address the role of concomitant medical or device therapies, stipulate all standard transplantation criteria, or measure the value of sequential therapies, such as CABG before transplantation. Assessment of myocardial viability, if available, is an important and early decision point that must be incorporated in the decision-making process for applicability of therapies; however, because of the paucity of data, we could not ascertain whether it influenced survival. The study's primary end point was all-cause time-related mortality, and we considered only maximizing survival. We did not measure quality-adjusted life years, costs, adverse cardiac events, readmissions for heart failure, or improvement in functional class, all of which might be important outcomes from the patient's, payer's, and society's perspectives. From an analytic perspective, the number of patients undergoing each therapy was modest, limiting the number of risk factors that could be identified reliably. Furthermore, we used only 1 holdout (test) sample; more sophisticated methods to calculate prediction error are becoming available. Finally, these and all models of longterm survival suffer from the rapid change of medical and surgical therapies, with difficult-to-quantify important incremental advances.

\section{Clinical Implications}

Optimal treatment of patients with advanced heart failure caused by ischemic heart disease needs to be assisted by real-time clinical decision-making tools. We envision, in the not-too-distant future, models that will predict survival with both medical and surgical therapies, left ventricular assist device support as bridge or destination therapy, and cardiac transplantation.

The authors thank Nichole Arcaro, Tanya Ashinhurst, Laurie Baines, Micah Davis, Theresa Garcia, Vi Huynh, Kexiao Liao, Areatha Lockridge, Eileene McClurkin, Michelle Miluk, Capri Spencer, Angela York, Kelly Polasko, Carolyn Apperson-Hansen, and Brian Kohlbacher for data collection, graphics, and review; Lucy Thuita, Jason Zhong, and John Ehrlinger for programming; Jocelyn Piskach, Iman Aziz, and Michelle Edwards for quality control; Lucinda Mitchin, Maureen Kidd, Colleen Vahcic, Lina Vargas, and Nicholas Krebs for logistical support; and Tess Parry for editorial revisions.

\section{References}

1. Allen LA, Felker GM. Advances in the surgical treatment of heart failure. Curr Opin Cardiol. 2008;23:249-53.

2. Boyle CA, Decoufle P. National sources of vital status information: extent of coverage and possible selectivity in reporting. Am J Epidemiol. 1990;131:160-8.

3. Newman TB, Brown AN. Use of commercial record linkage software and vital statistics to identify patient deaths. J Am Med Inform Assoc. 1997;4:233-7.

4. Blackstone EH, Naftel DC, Turner ME Jr. The decomposition of time-varying hazard into phases, each incorporating a separate stream of concomitant information. J Am Stat Assoc. 1986;81:615-24.

5. Blackstone EH. Breaking down barriers: helpful breakthrough statistical methods you need to understand better. J Thorac Cardiovasc Surg. 2001;122:430-9.

6. Breiman L. Bagging predictors. Machine Learning. 1996;24:123-40.

7. Drake C, Fisher L. Prognostic models and the propensity score. Int J Epidemiol. 1995;24:183-7.

8. Sergeant P, Blackstone E, Meyns B. Validation and interdependence with patientvariables of the influence of procedural variables on early and late survival after CABG.K.U. Leuven Coronary Surgery Program. Eur J Cardiothorac Surg. 1997; 12:1-19.

9. Gerds TA, Schumacher M. Consistent estimation of the expected Brier score in general survival models with right-censored event times. Biom J. 2006;48: $1029-40$.

10. Eagle KA, Guyton RA, Davidoff R, Edwards FH, Ewy GA, Gardner TJ, et al. ACC/AHA 2004 guideline update for coronary artery bypass graft surgery: a report of the American College of Cardiology/American Heart Association Task Force on Practice Guidelines (Committee to Update the 1999 Guidelines for Coronary Artery Bypass Graft Surgery). Circulation. 2004; 110:e340-437.

11. Tolis GA Jr, Korkolis DP, Kopf GS, Elefteriades JA. Revascularization alone (without mitral valve repair) suffices in patients with advanced ischemic cardiomyopathy and mild-to-moderate mitral regurgitation. Ann Thorac Surg. 2002; 74:1476-81.

12. Mihaljevic T, Lam BK, Rajeswaran J, Takagaki M, Lauer MS, Gillinov AM, et al Impact of mitral valve annuloplasty combined with revascularization in patients with functional ischemic mitral regurgitation. J Am Coll Cardiol. 2007;49: 2191-201.

13. Wu AH, Aaronson KD, Bolling SF, Pagani FD, Welch K, Koelling TM. Impact of mitral valve annuloplasty on mortality risk in patients with mitral regurgitation and left ventricular systolic dysfunction. J Am Coll Cardiol. 2005;45:381-7.

14. Gorman RC, Gorman JH. Invited commentary: Tolis GA, Jr. Korkolis DP, Kopf GS, Elefteriades JA. Revascularization alone (without mitral valve repair) suffices in patients with advanced ischemic cardiomyopathy and mild-to-moderate mitral regurgitation. Ann Thorac Surg. 2002;74:1481.

15. Velazquez EJ, Lee KL, O'Connor CM, Oh JK, Bonow RO, Pohost GM, et al. The rationale and design of the Surgical Treatment for Ischemic Heart Failure (STICH) trial. J Thorac Cardiovasc Surg. 2007;134:1540-7.

16. Maxey TS, Reece TB, Ellman PI, Butler PD, Kern JA, Tribble CG, et al. Coronary artery bypass with ventricular restoration is superior to coronary artery bypass alone in patients with ischemic cardiomyopathy. J Thorac Cardiovasc Surg. 2004; 127:428-34. 
17. Kron IL, Lerman BB, Haines DE, Flanagan TL, DiMarco JP. Coronary artery bypass grafting in patients with ventricular fibrillation. Ann Thorac Surg. 1989;48: 85-9.

18. Langenburg SE, Buchanan SA, Blackbourne LH, Scheri RP, Sinclair KN, Martinez J, et al. Predicting survival after coronary revascularization for ischemic cardiomyopathy. Ann Thorac Surg. 1995;60:1193-7.

19. Pasquet A, Lauer MS, Williams MJ, Secknus MA, Lytle B, Marwick TH. Prediction of global left ventricular function after bypass surgery in patients with severe left ventricular dysfunction. Impact of pre-operative myocardial function, perfusion, and metabolism. Eur Heart J. 2000;21:125-36.

20. Buckberg GD. Congestive heart failure: treat the disease, not the symptom-return to normalcy. J Thorac Cardiovasc Surg. 2001;121:628-37.

21. Ratcliffe MB, Guy TS. The effect of preoperative diastolic dysfunction on outcome after surgical ventricular remodeling. J Thorac Cardiovasc Surg. 2007; 134:280-3.

22. Burkhoff D, Wechsler AS. Surgical ventricular remodeling: a balancing act on systolic and diastolic properties. J Thorac Cardiovasc Surg. 2006;132:459-63.

23. Jones RH, Velazquez EJ, Michler RE, Sopko G, Oh JK, O'Connor CM, et al. Coronary bypass surgery with or without surgical ventricular reconstruction. $N$ Engl $J$ Med. 2009;360:1705-17.

24. Young JB. Heart failure's near dead and dying: reconsidering our heart transplant wait list scheme. J Am Coll Cardiol. 2007;50:1291-3.

25. Lietz K, Miller LW. Improved survival of patients with end-stage heart failure listed for heart transplantation: analysis of organ procurement and transplantation network/U.S. United Network of Organ Sharing data, 1990-2005. J Am Coll Cardiol. 2007;50:1282-90.

26. Murphy KM, Topel RH. Measuring the gains from medical research: an economic approach. Chicago: University of Chicago Press; 2003.

27. Ross PL, Scardino PT, Kattan MW. A catalog of prostate cancer nomograms. J Urol. 2001;165:1562-8.

28. Miller GA. The magical number seven, plus or minus two: some limits on our capacity for processing information. Psychol Rev. 1956;63:81-97.

29. Kareev Y. Seven (indeed, plus or minus two) and the detection of correlations. Psychol Rev. 2000;107:397-402.

30. Wright $P$. The harassed decision maker: time pressures, distractions, and the use of evidence. J Appl Psychol. 1974;59:555-61.

31. Nashef SA, Roques F, Michel P, Gauducheau E, Lemeshow S, Salamon R. European system for cardiac operative risk evaluation (EuroSCORE). Eur J Cardiothorac Surg. 1999;16:9-13.

32. Shroyer AL, Coombs LP, Peterson ED, Eiken MC, DeLong ER, Chen A, et al The Society of Thoracic Surgeons: 30-day operative mortality and morbidity risk models. Ann Thorac Surg. 2003;75:1856-65.

33. Levy WC, Mozaffarian D, Linker DT, Sutradhar SC, Anker SD, Cropp AB, et al. The Seattle Heart Failure Model: prediction of survival in heart failure. Circulation. 2006;113:1424-33.

34. Lietz K, Long J, Kfoury AG, Slaughter MS, Silver MA, Milano CA, et al. Outcomes of left ventricular assist device implantation as destination therapy in the post-REMATCH era: implications for patient selection. Circulation. 2007;116:497-505.

35. Reason J. Human error: models and management. BMJ. 2000;320:768-70.

36. Blackstone EH. Thinking beyond the risk factors. Eur J Cardiothorac Surg. 2006; 29:645-52.

\section{Discussion}

Dr Curtis G. Tribble (Gainesville, Fla). I have been handing out Dr Bruce Lytle's single-authored essay on this subject that was published in the Annals of Thoracic Surgery about 5 years ago to most of my junior house officers and students ever since he wrote it. It is a great article for anybody who would like to read about his thoughts at that time. His last sentences in that article state that (1) coronary artery bypass surgery is best for most of these patients with ischemic cardiomyopathy, (2) we do not know very much about any of the other options, and (3) the other options should be studied. Today's article presented by Mr Yoon is obviously an attempt to address that charge.

I have to admit, as a former English major, that I was a bit distracted and even fascinated by the language of this article, such as the "split-sample holdout." I am not going to ask you this, Dustin, but don't you think that sounds more like a poker game than a statistical test? Other terms were equally interesting, such as the "parsimonious variable selection," " the bagging bootstrap aggregation," and my favorite term in the article, "the cognitive prosthesis tool.' 'But all kidding aside, I did round up a real statistician and ask for some help in understanding all these terms, and I did learn, as I would have expected, that all these terms are not only real but quite valid statistical strategies.

I will also say that it is obvious that this study was a good-faith effort to answer Dr Lytle's earlier call for more clarity on the options for ischemic cardiomyopathy. There are lots of patients, there are hard end points, and there, indeed, are valid statistical strategies. However, one of my difficulties in thinking about this article is that clearly not all the options are truly available to all the patients, and, presumably, some thoughtful person made the original choice based on literally tens if not hundreds of bits of data, surely some of which are unknown to the later reviewer and, thus, difficult to study.

So to think more specifically about some of the numbers, it seems to me that although $75 \%$ of the total group of 1321 patients were well served by coronary artery bypass alone $(n=556)$ or by transplantation $(n=423)$, less than $4 \%(n=50)$ were well served by mitral valve repair combined with coronary bypass. I think this is a sobering assertion and leads me to my one question for you, Dustin, that you might have some insight into from your study along with other recent studies from your institution, such as Mark Gillinov's article presented at this meeting last year comparing mitral valve repair and mitral valve replacement in older patients, in which survival was not altered by the technique of treating the mitral valve.

Here is my question. Given that your model suggests that mitral valve repair should be done in so few patients with ischemic mitral regurgitation, do you think that it is possible that the patients with ischemic mitral valve regurgitation would have been better served with an mitral valve replacement instead of a mitral valve anuloplasty if this were done with the techniques of modern cardiac protection and chordal preservation, or is it the sense of you and your colleagues at the Cleveland Clinic that the regurgitant mitral valve in the setting of ischemic cardiomyopathy is best treated medically in the vast majority of cases?

Mr Yoon. Thank you very much for your comments and your question, Dr Tribble.

When we went back and analyzed alternative survival comparisons for $\mathrm{CABG}$ alone, $\mathrm{CABG}$ with concomitant SVR, and transplantation therapies, we found that mitral valve anuloplasty was recommended as the best therapy to optimize survival less than $2 \%$ of the time. As you say, these are sobering statistics, and I think they may provide some insight into which options have the best long-term outcomes. Mitral valve anuloplasty may not be the best option for these patients with ischemic mitral valve etiology.

In terms of Dr Gillinov's paper presented here last year, he looked at 195 propensity-matched pairs undergoing replacement versus repair for degenerative mitral valve disease and found no major survival difference between these 2 groups. Neither mitral valve repair nor replacement emerged as a risk factor that affected overall survival. 
We think that a common thread in all these studies is that, in these sicker patients with ischemic cardiomyopathy and multiple comorbidities, prognosis is poor whether you do replacement or repair. I believe that it will require a randomized trial to further elucidate these types of outcomes. My mentor, Dr Blackstone, has informed me that in July, the Cardiac Surgery Network plans to conduct a randomized trial looking specifically at these outcomes, at moderate and severe mitral regurgitation, and at the effects of repair versus replacement. The results will hopefully settle some of the controversy surrounding treatment options.

Dr Paul Kurlansky (Miami, Fla). This is a very provocative and interesting study. I look forward to the complete article to try to understand it better. I would like to exercise a word of caution, though, and perhaps it is related to the number of patients included and the number of variables that were available to you. In the example that you presented, a patient who had a certain risk-factor profile with lifestyle problems and smoking, lifestyle problems that led to diabetes as well as cigarette smoking, put him into the transplantation category. I think that shows probably one of the shortcomings of this approach because likely somebody who has lifestyle problems and smoking might not be an ideal candidate for transplantation and might not be accepted for transplantation.

Therefore, I think we wind up with a situation in which our clinical judgment might be even better than what the figures would suggest, and I was sort of wondering how you might solve some of these problems. Perhaps it might be wiser to view this sort of study as hypothesis generating rather than definitive.

Mr Yoon. Thank you very much for your comment, Dr Kurlansky. I think your point is well taken, and it is in fact the reason we used the term "decision support tool" rather than "decision making tool." In complex, real-world scenarios, I think a tool like this can synergistically augment a surgeon's capabilities by allowing not just 1 or 2 clinical variables to be taken into account when recommending the optimal surgical therapy but rather 3,4 , 5, or, in our case, hundreds of preoperative variables and their transformations. This is difficult for surgeons to fully assimilate, and studies have shown that clinicians usually think of the average result when it comes to variables, and not necessarily the magnitude. A support tool can help tremendously in this aspect.

In terms of applicability of each therapy, I think your point is also well taken in that not all of our patients were eligible for every treatment option. We tried to correct for this by setting eligibility criteria for our patient population. For example, to be eligible for SVR, a patient had to have anterior akinesia or dyskinesi, and also a left ventricular end diastolic diameter greater than $6 \mathrm{~cm}$. In fact, the STICH trial eligibility to enter the study was based on anterior akinesia or dyskinesia amenable to SVR and an ejection fraction of $35 \%$ or less. For transplantation, our patients had to be in New York Heart Association functional class III or IV, be less than 70 years old, and have a serum creatinine level of less than $1.7 \mathrm{mg} / \mathrm{dL}$. These broad criteria were set up to include all possible choices that an individual could have and not necessarily that they should undergo that particular surgery. The guidelines are just that-a possible path. The surgeon would make the final decision based on all available clinical information, imaging results, and final inspection in the operating room.

Dr John V. Conte, Jr (Baltimore, Md). I would like to congratulate you on a flawlessly presented article, and I would like to commend your mentors and co-authors on helping you to prepare such a nice presentation. I know how much work it takes, and I think this kind of mentoring is what we need to do more of in our specialty, particularly allowing junior members of our profession to present at national meetings.

The one comment I would like to make other than congratulating you and your co-authors is that this is a very intriguing article; however, the hypothesis does not help many people with decision making in the real world. The reality is we do not have transplantation as an option that is readily available at the times that we often would like for such patients, and also your inclusion of patients undergoing SVR who had an infarction as recently as 30 days also does not correlate with what we would generally recommend. We would not perform that operation for most patients who have had an infarction that recently.

Those limitations being noted, I think it does provide questions for us when we are selecting options for our patients, and again, I want to congratulate you on a nice job.

Mr Yoon. Thank you very much, Dr Conte. As part of our inclusion criteria, all patients in the study had a myocardial infarction greater than 30 days before surgery. In our SVR population, the median time between infarction and surgery was 3 years, so your point is valid. The decision to pursue SVR includes MRI studies, viability, and final inspection in the operating room, some factors that we did not and cannot incorporate into our models. Also, you are absolutely right that fewer than $10 \%$ of eligible recipients actually receive a heart transplantation. This is the reason we need to evaluate other treatment options for cardiomyopathy and know, as best as possible, the risks and survival benefits of these alternative treatments. Clearly, all the issues you raise are important.

Dr Charles C. Canver (Riyadh, Saudi Arabia). This is a very intriguing article. When I began to listen, I was hoping that you were going to come up with a model, almost a calculator, that would help to solve this complex problem. As you know, ischemic cardiomyopathy is a syndrome that cannot be caused by a single process. Unfortunately, this model is not capable of really answering the clinical questions. In reality, the decision is made by the use of many tests that assesses the viability of the myocardium in light of the patient's symptoms. Furthermore, I had difficulty accepting that your 51-year-old patient with a $4+$ MR and $10 \%$ ejection fraction could be best treated with CABG alone. In the actual clinical setting, I do not think anybody would tackle that problem with CABG alone.

I am very intrigued by young individuals, such as yourself, who are trying to bring new preoperative calculation methods to help us make a better decision in complex clinical dilemmas. Although that is a very nice thing to do, I am still skeptical. Your clinical model certainly does not address the real clinical issues. However, I do want to congratulate you for your nice work.

Mr Yoon. Again, with this decision support tool, we have made small but significant steps toward a clinical tool that can be accurately and reliably used in the clinical setting. In the future, we will continue trying to elucidate these many and variable factors that surgeons must deal with in the real clinical world. We also anticipate prospective and external validation of our tool and will take steps for its generalizability to the outside population. Thank you for your comments, Dr Canver; I will definitely keep them in mind. 


\section{APPENDIX 1. Variables used in analyses}

Demographic: Age (y), sex, weight $(\mathrm{kg})$, height $(\mathrm{cm})$, body surface area $\left(\mathrm{m}^{2}\right)$, body mass index $\left(\mathrm{kg} \cdot \mathrm{m}^{-2}\right)$

Symptoms: New York Heart Association functional class (I-IV), Canadian Angina Class (0-4), atypical angina, angina (rest pain, unstable angina), clinical symptoms (dyspnea, dyspnea on exertion, paroxysmal nocturnal dyspnea, orthopnea, peripheral edema, pulmonary edema-and their timing (history, current, both history and current)

Ventricular dysfunction: Degree of left ventricular dysfunction $(1=$ none, $2=$ mild, $3=$ moderate, $4=$ severe $)$, ejection fraction ( $\%)$, interval from date of most recent myocardial infarction to date of operation

Valve pathology: Aortic valve stenosis (presence and grades 0-5), aortic valve regurgitation (presence and grades $0-4+$ ), mitral valve regurgitation (grades $0-4$ ), tricuspid valve regurgitation (grades $0-4$ )

Coronary anatomy: Left main trunk disease (maximum \% stenosis), left anterior descending coronary artery system disease (maximum \% stenosis), right coronary artery system disease (maximum \% stenosis), left circumflex coronary artery system disease (maximum \% stenosis)

Other cardiac comorbidity: Atrial fibrillation, family history of ischemic heart disease, complete heart block, ventricular arrhythmia

Noncardiac comorbidity: Treated diabetes, insulin-treated diabetes, hypertension, history of smoking, carotid disease, popliteal disease, peripheral arterial disease, creatinine $\left(\mathrm{mg} \cdot \mathrm{dL}^{-1}\right)$, creatinine clearance $\left(\mathrm{mg} \cdot \mathrm{dL}^{-1}\right)$, blood urea nitrogen $\left(\mathrm{mg} \cdot \mathrm{dL}^{-1}\right)$, bilirubin $\left(\mathrm{mg} \cdot \mathrm{dL}^{-1}\right)$, hematocrit $(\%)$

Experience: Date of operation (years from January 1, 1997, to operation or listing)

\section{METHODS}

\section{Data Analysis}

Survival was estimated nonparametrically by using the Kaplan-Meier method and parametrically by using a multiphase hazard model. ${ }^{\mathrm{E} 1}$ The parametric model was used to resolve the number of phases of instantaneous risk of death (hazard function) and to estimate shaping parameters. (For additional details, see http://www.clevelandclinic.org/heartcenter/hazard.)

Model development. A split-sample (holdout) method was used to create a random $80 \%$ training and $20 \%$ test data set for each surgical therapy. By using only the training data sets, a parsimonious risk-factor model for mortality was created for each therapy. For these, multivariable analysis of preoperative variables (Appendix 1) was performed in the multiphase hazard function domain. Therapy-specific analyses were performed in part because the hazard functions were of different shapes (Figure E1) but primarily as a strategic approach because not all therapies are applicable to each patient.

Parsimonious variable selection used bagging (bootstrap aggregation) ${ }^{\mathrm{E} 2, \mathrm{E} 3}$ and 1000 bootstrap samples, with a $P$ value criterion for retention of variables in automated stepwise variable selection of .05. Frequency of occurrence of variables identified in these analyses indicated the reliability of each variable's association with mortality at a $P$ value of .05 or less. Variables with $50 \%$ or more reliability were retained in the parsimonious model.

Risk factors identified in any of the 4 models were then incorporated into a semisaturated model for each therapy. After validation, as described in the text that follows, the entire data set was used to generate the 4 final models from which the strategic decision aid was constructed (Table E5).

Group comparisons with propensity scores were inappropriate because the study's purpose was to identify risk factors for each treatment and predict survival for an individual's personal characteristics and condition. ${ }^{\mathrm{E} 4}$ Propensity score techniques are a substitute for randomized trials and address, just as randomization does, selection bias. ${ }^{\mathrm{E} 5 \mathrm{E} 6}$ Identical to a randomized trial, they focus on group comparisons of outcome (in well-matched patients). These methods are not used to analyze the full spectrum of patients but rather compare the subset of patients with overlapping characteristics.

Model validation. The 4 semisaturated models were used to predict survival of each patient in the holdout sample (20\% of each therapy). Two validation criteria were used: (1) conservation of events, comparing with a $\chi^{2}$ goodness-of-fit test the number of observed deaths versus predicted deaths calculated from estimated cumulative hazard at the end of each patient's follow-up, ${ }^{\mathrm{E} 7}$ and (2) comparison of observed versus predicted survival. For the latter, the weighted Brier score, ${ }^{\mathrm{E} 8}$ which provides a measure of discrepancy between observed and expected survival in the holdout sample, was estimated at each observed event time point. The smaller the Brier score, the better the prediction. A Brier score of 0.25 indicates no better than random prediction; hence we use 0.25 as the reference value.

\section{References}

E1. Blackstone EH, Naftel DC, Turner ME Jr. The decomposition of time-varying hazard into phases, each incorporating a separate stream of concomitant information. J Am Stat Assoc. 1986;81:615-24.

E2. Blackstone EH. Breaking down barriers: helpful breakthrough statistical methods you need to understand better. J Thorac Cardiovasc Surg. 2001;122:430-9.

E3. Breiman L. Bagging predictors. Machine Learning. 1996;24:123-40.

E4. Drake C, Fisher L. Prognostic models and the propensity score. Int J Epidemiol. 1995;24:183-7.

E5. Rosenbaum PR, Rubin DB. The central role of the propensity score in observational studies for causal effects. Biometrika. 1983;70:41-55.

E6. Rubin DB. The design versus the analysis of observational studies for causal effects: parallels with the design of randomized trials. Stat Med. 2007;26:20-36.

E7. Sergeant P, Blackstone E, Meyns B. Validation and interdependence with patientvariables of the influence of procedural variables on early and late survival after CABG.K.U. Leuven Coronary Surgery Program. Eur J Cardiothorac Surg. 1997; 12:1-19.

E8. Gerds TA, Schumacher M. Consistent estimation of the expected Brier score in general survival models with right-censored event times. Biom J. 2006;48: 1029-40. 

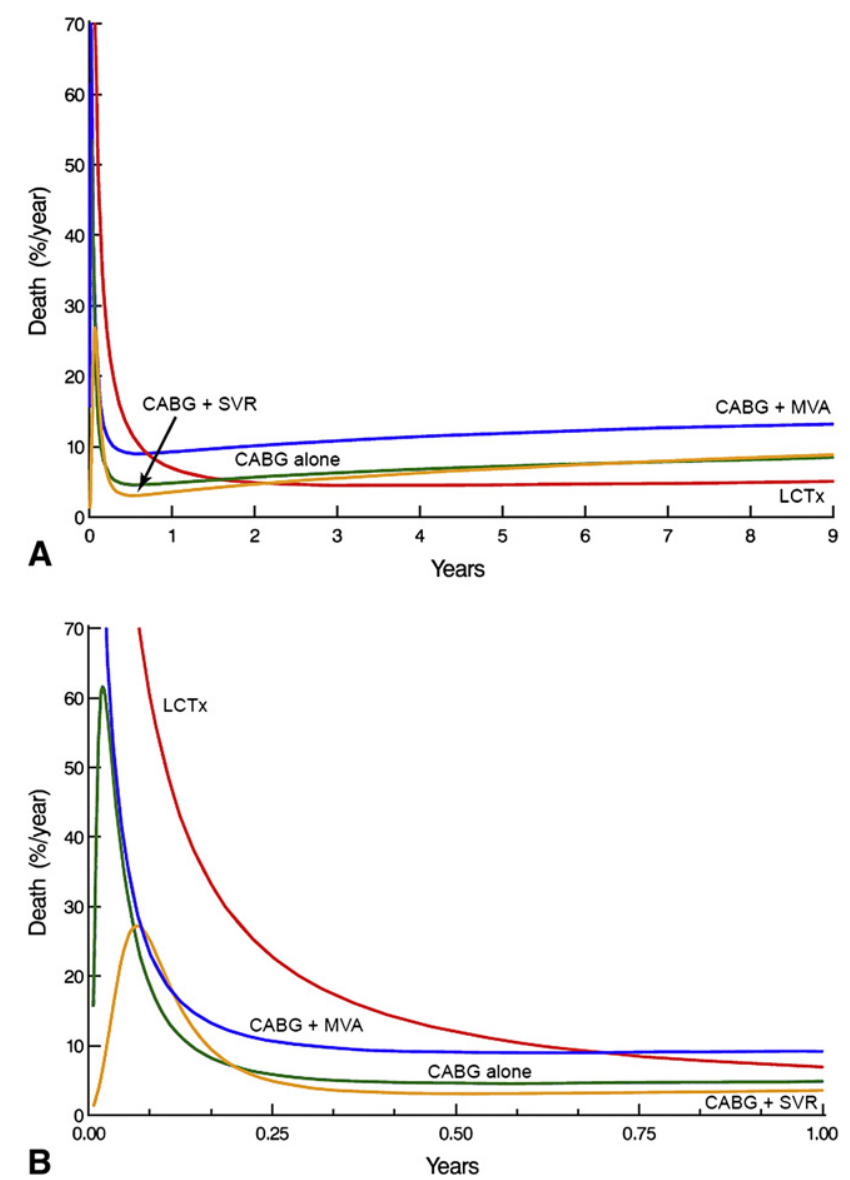

FIGURE E1. Instantaneous risk of death (hazard function after each surgical therapy for ischemic cardiomyopathy). A, Risk of death to 9 years. B, Risk of death within first year. Solid lines are parametric estimates. $C A B G$, Coronary artery bypass grafting; SVR, surgical ventricular restoration; $M V A$, mitral valve anuloplasty; $L C T x$, listing for cardiac transplantation. 

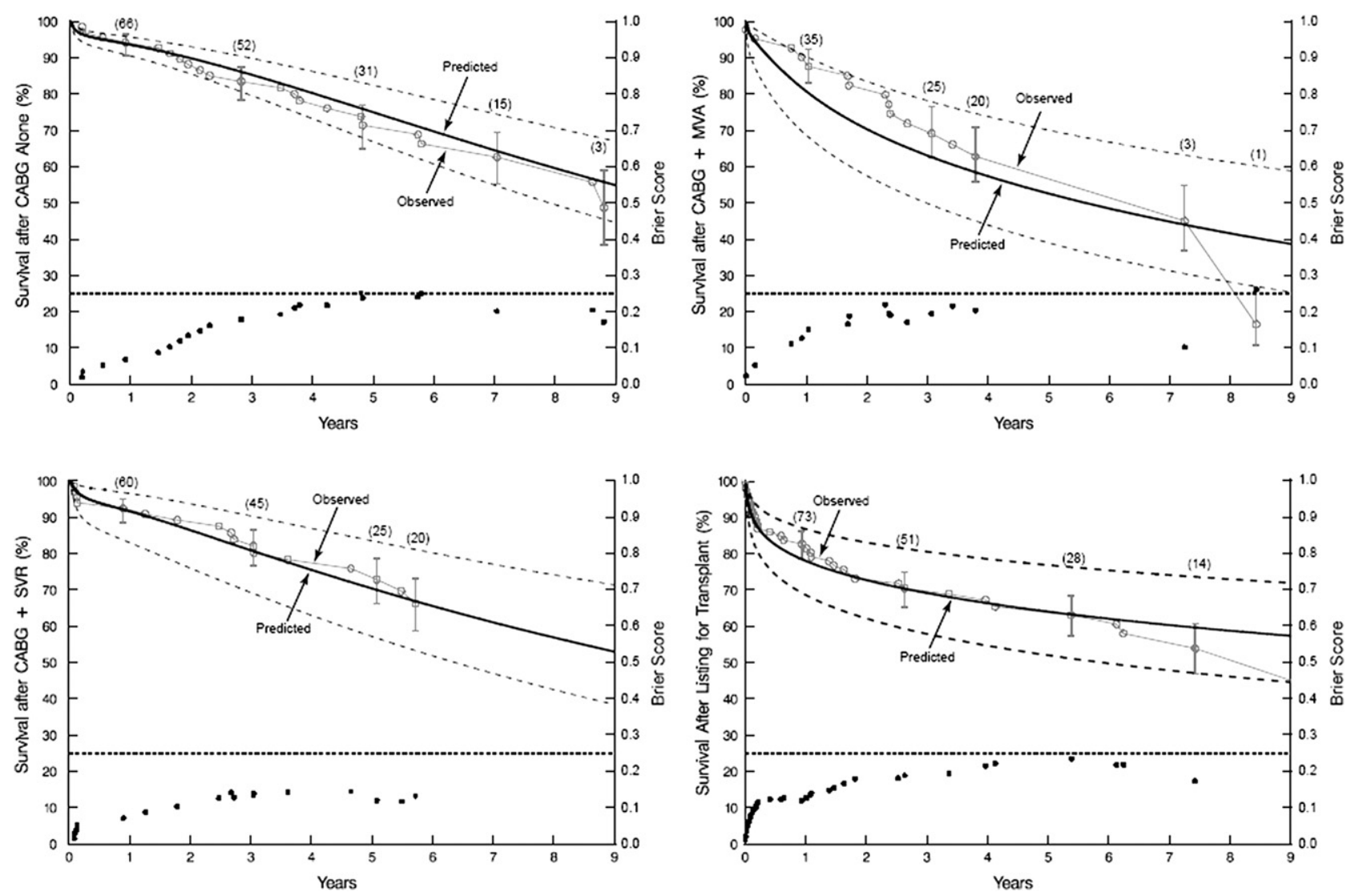

FIGURE E2. Graphic comparisons of model validation for each therapy. Solid lines enclosed within dashed $68 \%$ confidence limits are predicted survival estimates, symbols and vertical $68 \%$ confidence bars are Kaplan-Meier estimates of actual survival in the $20 \%$ holdout samples, and numbers in parentheses represent patients remaining at risk. Dots are Brier scores at each event time point, with the 0.25 line as the reference value below which predicted and observed survival are deemed appropriate. $C A B G$, Coronary artery bypass grafting; $S V R$, surgical ventricular restoration; $M V A$, mitral valve anuloplasty; LCTx, listing for cardiac transplantation. 

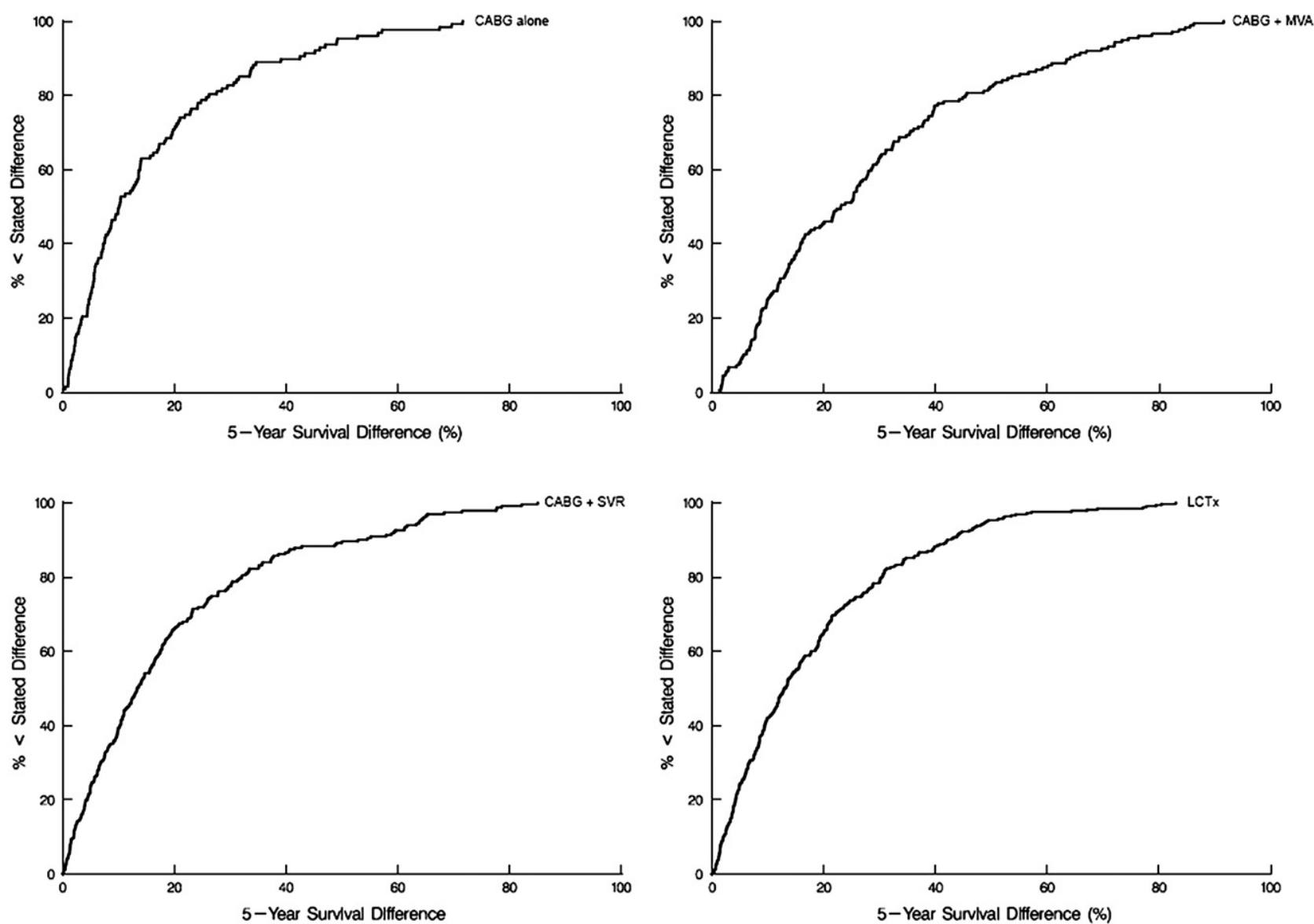

FIGURE E3. Cumulative 5-year survival difference between therapy received and therapy maximizing survival. Differences were calculated only for patients for whom an alternative therapy to the one received was predicted to provide greater 5 -year survival. $C A B G$, Coronary artery bypass grafting; $S V R$, surgical ventricular restoration; $M V A$, mitral valve anuloplasty; $L C T x$, listing for cardiac transplantation. 
TABLE E1. Myocardial viability by surgical therapy

\begin{tabular}{|c|c|c|c|c|c|c|c|c|c|}
\hline \multirow[b]{2}{*}{ Variable } & \multicolumn{2}{|c|}{$\begin{array}{c}\text { CABG alone } \\
\text { (total } \mathbf{n}=\mathbf{3 8 6} \text { ) }\end{array}$} & \multicolumn{2}{|c|}{$\begin{array}{c}\text { CABG }+ \text { MVA } \\
\text { (total } \mathbf{n}=\mathbf{2 1 2} \text { ) } \\
\end{array}$} & \multicolumn{2}{|c|}{$\begin{array}{c}\text { CABG }+ \text { SVR } \\
(\text { total } \mathbf{n}=\mathbf{3 6 0})\end{array}$} & \multicolumn{2}{|c|}{$\begin{array}{c}\text { LCTx } \\
(\text { total } \mathbf{n}=\mathbf{5 1 0}) \\
\end{array}$} & \multirow[b]{2}{*}{$\begin{array}{c}P \\
\text { value }\end{array}$} \\
\hline & $\mathbf{n}^{*}$ & $\begin{array}{c}\text { Mean } \pm \text { SD or } \\
\text { 15th/50th/85th } \\
\text { percentiles }\end{array}$ & n* & $\begin{array}{c}\text { Mean } \pm \text { SD or } \\
\text { 15th/50th/85th } \\
\text { percentiles }\end{array}$ & $n^{*}$ & $\begin{array}{c}\text { Mean } \pm \text { SD or } \\
\text { 15th/50th/85th } \\
\text { percentiles }\end{array}$ & $\mathbf{n}^{*}$ & $\begin{array}{c}\text { Mean } \pm \text { SD or } \\
\text { 15th/50th/85th } \\
\text { percentiles }\end{array}$ & \\
\hline \multicolumn{10}{|l|}{ CMR imaging } \\
\hline Transmurality score $\dagger$ & 28 & $0 / 2 / 6$ & 25 & $0 / 2 / 6.2$ & 92 & $2 / 6 / 8$ & 8 & $5 / 8 / 10$ & $<.0001$ \\
\hline Total scar score $\ddagger$ & 28 & $1.04 \pm 0.71$ & 25 & $1.1 \pm 0.84$ & 92 & $1.8 \pm 0.63$ & 8 & $2.4 \pm 0.52$ & $<.0001$ \\
\hline \multicolumn{10}{|l|}{ Dobutamine echocardiography } \\
\hline Transmurality score $\S$ & 33 & $8.1 \pm 2.4$ & 14 & $7.6 \pm 3.6$ & 52 & $8.6 \pm 2.3$ & 12 & $8.7 \pm 4.3$ & .2 \\
\hline Total scar score $\|$ & 33 & $2.2 \pm 0.41$ & 14 & $2.1 \pm 0.70$ & 52 & $2.2 \pm 0.40$ & 12 & $2.3 \pm 0.77$ & .2 \\
\hline \multicolumn{10}{|l|}{ FDG-PET } \\
\hline Transmurality score $\mathbb{9}$ & 5 & $0 / 2 / 6.5$ & 6 & $0 / 0 / 5$ & 1 & 1.2 & 3 & $0 / 1.5 / 3.6$ & .7 \\
\hline Total scar score $\ddagger$ & 5 & 0/0.71/1.6 & 6 & $0 / 0.47 / 1.6$ & 1 & 0 & 3 & $0.12 / 0.42 / 0.9$ & .5 \\
\hline \multicolumn{10}{|l|}{ SPECT } \\
\hline Transmurality score ${ }^{\#}$ & 4 & $0 / 0 / 2$ & 3 & $0 / 0 / 1.6$ & 0 & - & 4 & $0 / 0 / 0$ & .4 \\
\hline Total scar score $\ddagger$ & 4 & $0 / 0 / 0.51$ & 3 & $0 / 0 / 0.55$ & 0 & - & 4 & 0/0/0.07 & .7 \\
\hline \multicolumn{10}{|l|}{ Thallium } \\
\hline Transmurality score ${ }^{* *}$ & 3 & $0 / 1 / 2$ & 2 & $0 / 1 / 2$ & 0 & - & 2 & $0 / 1 / 2$ & .4 \\
\hline Total scar score $\ddagger$ & 3 & $0 / 0.21 / 0.54$ & 2 & $0 / 0.21 / 0.54$ & 0 & - & 2 & $0 / 0.21 / 0.54$ & .7 \\
\hline Patients with $\geq 1$ viability study & 84 & & 53 & & 179 & & 33 & & \\
\hline
\end{tabular}

$C A B G$, Coronary artery bypass grafting; $M V A$, mitral valve anuloplasty; $S V R$, surgical ventricular restoration; $L C T x$, listing for cardiac transplantation; $S D$, standard deviation; $C M R$, cardiac magnetic resonance; FDG-PET, fluorodeoxyglucose positron emission tomography; SPECT, 99-mTc-single photon emission computed tomography. *Number of patients with data available. $\nmid$ Number of segments with a CMR segmental scar score of 3 or 4 . $\ddagger$ Summed segmental scar scores/patient $\div 17$ (reflecting damage/patient). $\S$ Normal $=0$, mildly hypokinetic $=1$, severely hypokinetic $=2$, akinetic $=3$, dyskinetic/aneurysmal $=4$. $\|$ Summed segmental scar scores $\div 16$ (reflecting damage/patient). $\uparrow$ Number of segments with an FDG-PET segmental scar score of 3 or 4 . \#Number of segments with an SPECT segmental scar score of 3 or 4 . **Number of segments with a thallium segmental scar score of 3 or 4 .

TABLE E2. In-hospital outcomes by surgical therapy*

\begin{tabular}{|c|c|c|c|c|c|}
\hline & $\begin{array}{c}\text { CABG alone } \\
(\mathbf{n}=\mathbf{3 8 6})\end{array}$ & $\begin{array}{c}\text { CABG }+ \text { MVA } \\
(\mathbf{n}=\mathbf{2 1 2})\end{array}$ & $\begin{array}{c}\text { CABG }+ \text { SVR } \\
(\mathbf{n}=\mathbf{3 6 0})\end{array}$ & $\begin{array}{c}\text { Heart transplantation } \dagger \\
(\mathbf{n}=\mathbf{3 4 8})\end{array}$ & \\
\hline Variable & $\begin{array}{c}\text { No. }(\%) \text { or } \\
\text { 15th/50th/85th } \\
\text { percentiles }\end{array}$ & $\begin{array}{c}\text { No. }(\%) \text { or } \\
\text { 15th/50th/85th } \\
\text { percentiles }\end{array}$ & $\begin{array}{c}\text { No. }(\%) \text { or } \\
\text { 15th/50th/85th } \\
\text { percentiles }\end{array}$ & $\begin{array}{l}\text { No. }(\%) \text { or } \\
\text { 15th/50th/85th } \\
\text { percentiles }\end{array}$ & $P$ value \\
\hline Hospital mortality & $\begin{array}{c}7(1.8) \\
(68 \% \mathrm{CL}, 1.2-2.8)\end{array}$ & $\begin{array}{c}9(4.2) \\
(68 \% \text { CL, } 2.9-6.1)\end{array}$ & $\begin{array}{c}9(2.5) \\
(68 \% \mathrm{CL}, 1.7-3.6)\end{array}$ & $\begin{array}{c}18(5.2) \\
(68 \% \mathrm{CL}, 3.1-5.4)\end{array}$ & .05 \\
\hline Respiratory insufficiency & $29(7.5)$ & $25(12)$ & $33(9.2)$ & $47(14)$ & .04 \\
\hline IABP $\ddagger$ & $14(3.6)$ & $21(9.9)$ & $31(8.6)$ & $19(5.5)$ & .006 \\
\hline Return to OR for bleeding & $12(3.1)$ & $9(4.2)$ & $14(3.9)$ & $39(11)$ & $<.0001$ \\
\hline Septicemia/sepsis & $8(2.1)$ & $11(5.2)$ & $21(5.8)$ & $43(12)$ & $<.0001$ \\
\hline Stroke & $6(1.6)$ & $3(1.4)$ & $3(0.83)$ & $6(1.7)$ & .8 \\
\hline Myocardial infarction & $1(0.26)$ & $0(0)$ & $2(0.56)$ & $0(0)$ & .4 \\
\hline Renal failure & $5(1.3)$ & $10(4.7)$ & $5(1.4)$ & $16(4.6)$ & .004 \\
\hline \multicolumn{6}{|l|}{ Length of stay (d) } \\
\hline ICU & $1 / 2 / 4$ & $1 / 3 / 6$ & $1 / 2 / 6$ & $2 / 3 / 8$ & $<.0001$ \\
\hline Postoperative & $5 / 7 / 12$ & $6 / 9 / 19$ & $6 / 9 / 17$ & $9 / 14 / 26$ & $<.0001$ \\
\hline Hospital & $6 / 10 / 19$ & $7 / 14 / 26$ & $7 / 12 / 23$ & $13 / 32 / 83$ & $<.0001$ \\
\hline
\end{tabular}


TABLE E3. Incremental risk factors for death by surgical management group: Semisaturated model

\begin{tabular}{|c|c|c|c|c|c|c|c|c|}
\hline \multirow[b]{2}{*}{ Factor } & \multicolumn{2}{|c|}{$\begin{array}{c}\text { CABG alone } \\
\text { (total } \mathbf{n}=\mathbf{3 8 6} \text { ) }\end{array}$} & \multicolumn{2}{|c|}{$\begin{array}{c}\text { CABG }+ \text { MVA } \\
(\text { total } n=212)\end{array}$} & \multicolumn{2}{|c|}{$\begin{array}{c}\text { CABG }+ \text { SVR } \\
(\text { total } \mathbf{n}=\mathbf{3 6 0})\end{array}$} & \multicolumn{2}{|c|}{$\begin{array}{c}\text { LCTx } \\
(\text { total } n=510)\end{array}$} \\
\hline & $\begin{array}{c}\text { Coefficient } \\
\quad \pm \text { SE }\end{array}$ & $\begin{array}{c}P \\
\text { value }\end{array}$ & $\begin{array}{c}\text { Coefficient } \\
\pm \mathrm{SE}\end{array}$ & $\begin{array}{c}P \\
\text { value }\end{array}$ & $\begin{array}{c}\text { Coefficient } \\
\pm \text { SE }\end{array}$ & $\begin{array}{c}P \\
\text { value }\end{array}$ & $\begin{array}{l}\text { Coefficient } \\
\pm \mathrm{SE}\end{array}$ & $\begin{array}{c}P \\
\text { value }\end{array}$ \\
\hline \multicolumn{9}{|l|}{ Early hazard phase } \\
\hline Age* & $-0.94 \pm 1.6$ & .6 & $-11 \pm 5.4 \dagger$ & .04 & $-0.02 \pm 0.43$ & $>.9$ & $1.5 \pm 1.1$ & .2 \\
\hline $\begin{array}{l}\text { NYHA functional } \\
\text { class III/IV }\end{array}$ & $1.7 \pm 0.69$ & .01 & $26 \pm 9146$ & $>.9$ & $1.3 \pm 0.71$ & .07 & $11 \pm 73$ & .9 \\
\hline 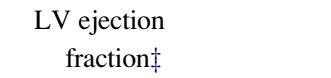 & $0.59 \pm 1.4$ & .7 & $-6.1 \pm 3.1$ & .05 & $-2.1 \pm 0.81$ & .008 & $-0.62 \pm 0.55$ & .3 \\
\hline Canadian Angina Class & $-0.100 \pm 0.22$ & 6 & $-0.400 \pm 0.51$ & .4 & $0.53 \pm 0.24$ & .03 & $-0.019 \pm 0.16$ & .9 \\
\hline Ventricular arrhythmia & $0.17 \pm 0.68$ & .8 & $18 \pm 1829$ & $>.9$ & $-0.404 \pm 0.82$ & .6 & $0.56 \pm 0.42$ & .2 \\
\hline $\begin{array}{l}\text { Three-system coronary } \\
\text { disease }\end{array}$ & $-0.17 \pm 0.53$ & .7 & $-1.1 \pm 1.6$ & .5 & $0.39 \pm 0.63$ & .5 & $0.94 \pm 0.43$ & .03 \\
\hline Previous stroke & $1.3 \pm 0.61$ & .03 & $7.4 \pm 3.1$ & .01 & $1.5 \pm 0.68$ & .02 & $1.3 \pm 0.51$ & .01 \\
\hline BUN $\S$ & $0.011 \pm 0.094$ & .9 & $-1.4 \pm 1.01$ & .2 & $0.14 \pm 0.074$ & .05 & $0.088 \pm 0.021$ & $<.0001$ \\
\hline Bilirubin & $0.19 \pm 0.31$ & .5 & $1.2 \pm 0.74$ & .09 & $0.39 \pm 0.51 \|$ & .4 & $0.53 \pm 0.12$ & $<.0001$ \\
\hline \multicolumn{9}{|l|}{ Late hazard phase } \\
\hline Complete heart block & $0.26 \pm 0.64$ & .7 & $0.48 \pm 0.39$ & .2 & $-0.92 \pm 0.53$ & .08 & $-0.44 \pm 0.34$ & .2 \\
\hline Ventricular arrhythmia & $0.300 \pm 0.32$ & .4 & $0.51 \pm 0.31$ & .1 & $-0.50 \pm 0.42$ & .2 & $0.55 \pm 0.24$ & .02 \\
\hline COPD & $1.3 \pm 0.29$ & $<.0001$ & $-0.38 \pm 0.29$ & .9 & $0.068 \pm 0.28$ & .8 & $0.21 \pm 0.29$ & .5 \\
\hline Renal disease & $0.57 \pm 0.42$ & .2 & $0.94 \pm 0.38$ & .01 & $-0.59 \pm 0.76$ & .4 & $0.51 \pm 0.25$ & .05 \\
\hline Age & $0.42 \pm 0.19$ & .03 & $0.049 \pm 0.24$ & .8 & $0.36 \pm 0.26$ & .2 & $0.050 \pm 0.21$ & .8 \\
\hline $\begin{array}{l}\text { LV ejection } \\
\text { fraction }^{\#}\end{array}$ & $-0.27 \pm 0.34$ & .4 & $0.103 \pm 0.33$ & .8 & $-0.94 \pm 0.32$ & .004 & $-0.030 \pm 0.12$ & .8 \\
\hline Atrial fibrillation & $0.71 \pm 0.58$ & .2 & $-0.17 \pm 0.45$ & .7 & $1.1 \pm 0.500$ & .03 & $0.14 \pm 0.23$ & .5 \\
\hline $\begin{array}{l}\text { Left main disease } \\
\text { (any stenosis) }\end{array}$ & $0.015 \pm 0.31$ & $>.9$ & $-0.16 \pm 0.28$ & 6 & $0.59 \pm 0.300$ & .05 & $0.44 \pm 0.25$ & .08 \\
\hline $\begin{array}{l}\text { RCA disease }(\geq 50 \% \\
\text { stenosis })\end{array}$ & $0.68 \pm 0.49$ & .2 & $0.404 \pm 0.52$ & .4 & $0.65 \pm 0.36$ & .07 & $0.36 \pm 0.31$ & .2 \\
\hline $\begin{array}{l}\text { LCx disease }(\geq 70 \% \\
\text { stenosis) }\end{array}$ & $0.049 \pm 0.31$ & .9 & $0.71 \pm 0.35$ & .04 & $0.062 \pm 0.29$ & .8 & $0.083 \pm 0.25$ & .7 \\
\hline $\mathrm{AV}$ regurgitation & $0.300 \pm 0.37$ & .4 & $0.0038 \pm 0.38$ & $>.9$ & $1.02 \pm 0.33$ & .002 & $0.96 \pm 0.25$ & .0001 \\
\hline $\begin{array}{l}\text { Interval from MI to } \\
\text { operation/listing** }\end{array}$ & $-0.21 \pm 0.12$ & .08 & $0.021 \pm 0.0091 \dagger \dagger$ & .02 & $0.22 \pm 0.14 t \ddagger$ & .1 & $0.016 \pm 0.011 \dagger \dagger$ & .2 \\
\hline Popliteal disease & $0.77 \pm 0.32$ & .02 & $-0.11 \pm 0.33$ & .7 & $-1.02 \pm 0.52$ & .05 & $-0.29 \pm 0.35$ & .4 \\
\hline Treated diabetes & $0.68 \pm 0.31$ & .03 & $-0.0086 \pm 0.37$ & $>.9$ & $0.075 \pm 0.37$ & .4 & $0.66 \pm 0.29$ & .02 \\
\hline Insulin-treated diabetes & $0.29 \pm 0.35$ & .4 & $0.73 \pm 0.44$ & .1 & $0.64 \pm 0.47$ & .2 & $-0.24 \pm 0.36$ & .5 \\
\hline Cholesterol $\S \S$ & $-3.5 \pm 0.11$ & .002 & $0.56 \pm 0.74$ & .4 & $1.1 \pm 0.92$ & .2 & $-0.504 \pm 0.36$ & .2 \\
\hline BUN \|\| & $0.26 \pm 0.32$ & .4 & $1.3 \pm 0.35$ & .0004 & $0.78 \pm 0.34$ & .02 & $-0.15 \pm 0.26$ & .6 \\
\hline Peripheral arterial disease & $-0.096 \pm 0.29$ & .7 & $0.18 \pm 0.34$ & .6 & $0.41 \pm 0.29$ & .1 & $0.600 \pm 0.24$ & .01 \\
\hline Hematocrit $\llbracket \rrbracket$ & $-13 \pm 38^{\# \#}$ & .7 & $-1.3 \pm 0.93$ & .2 & $-4.6 \pm 1.02$ & $<.0001$ & $-2.6 \pm 0.704$ & .0003 \\
\hline
\end{tabular}

$C A B G$, Coronary artery bypass grafting; $M V A$, mitral valve anuloplasty; $S V R$, surgical ventricular restoration; $L C T x$, listing for cardiac transplantation; $S E$, standard error; $N Y H A$, New York Heart Association; $L V$, left ventricular; $B U N$, blood urea nitrogen; $C O P D$, chronic obstructive pulmonary disease; $R C A$, right coronary artery; $L C x$, left circumflex coronary artery; $A V$, atrioventricular; $M I$, myocardial infarction.

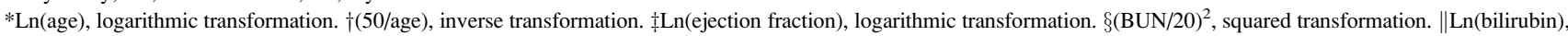
logarithmic transformation. $\lceil\operatorname{Exp}($ age/50), exponential transformation. \#(Ejection fraction/20), squared transformation. **(4/[interval from MI to operation+1]), inverse transfor-

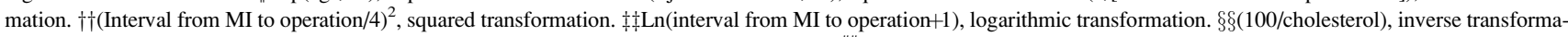

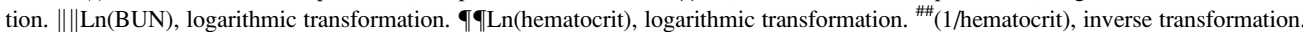


TABLE E4. Model validation using the conservation-of-events method

\begin{tabular}{lccc}
\hline & \multicolumn{2}{c}{ No. of deaths } & \\
\cline { 2 - 3 } \multicolumn{1}{c}{ Surgical therapy } & Observed & Predicted & $\boldsymbol{P}$ value \\
\hline CABG alone & 22 & 25.5 & .4 \\
CABG + MVA & 11 & 12.1 & .7 \\
CABG + SVR & 15 & 14.5 & .9 \\
LCTx & 31 & 24.7 & .14 \\
\hline
\end{tabular}

$C A B G$, Coronary artery bypass grafting; $M V A$, mitral valve anuloplasty; $S V R$, surgical ventricular restoration; $L C T x$, listing for cardiac transplantation.
TABLE E5. Incremental risk factors for death for patient-specific model

\begin{tabular}{|c|c|c|c|c|}
\hline Factor & $\begin{array}{c}\text { Scenario } \\
\text { A }\end{array}$ & $\begin{array}{c}\text { Scenario } \\
\text { B }\end{array}$ & $\begin{array}{c}\text { Scenario } \\
\text { C }\end{array}$ & $\begin{array}{c}\text { Scenario } \\
\text { D }\end{array}$ \\
\hline \multicolumn{5}{|l|}{ Demography } \\
\hline Age (y) & 53 & 53 & 53 & 53 \\
\hline \multicolumn{5}{|l|}{ Cardiac comorbidity } \\
\hline $\begin{array}{l}\text { LCx disease }(\geq 70 \% \\
\text { stenosis })\end{array}$ & 0 & 0 & 0 & 1 \\
\hline $\begin{array}{l}\text { RCA disease }(\geq 50 \% \\
\text { stenosis) }\end{array}$ & 0 & 0 & 1 & 1 \\
\hline $\begin{array}{l}\text { Left main disease (any } \\
\text { stenosis) }\end{array}$ & 1 & 1 & 0 & 1 \\
\hline $\begin{array}{l}\text { Three-system coronary } \\
\text { disease }\end{array}$ & 0 & 0 & 1 & 1 \\
\hline $\begin{array}{l}\text { LV ejection } \\
\quad \text { fraction }(\%)\end{array}$ & 25 & 25 & 25 & 25 \\
\hline $\begin{array}{l}\text { Interval from } \\
\text { MI to operation (y) }\end{array}$ & 2.1 & 5 & 2.1 & 2.1 \\
\hline Atrial fibrillation & 0 & 1 & 1 & 1 \\
\hline $\begin{array}{l}\text { Aortic valve } \\
\text { regurgitation }\end{array}$ & 0 & 0 & 1 & 1 \\
\hline \multicolumn{5}{|l|}{ Clinical symptoms } \\
\hline $\begin{array}{l}\text { NYHA functional } \\
\text { class III/IV }\end{array}$ & 1 & 1 & 1 & 1 \\
\hline Canadian Angina Class & 4 & 4 & 4 & 4 \\
\hline Complete heart block & 1 & 1 & 0 & 0 \\
\hline Ventricular arrhythmia & 0 & 0 & 0 & 1 \\
\hline \multicolumn{5}{|l|}{ Noncardiac comorbidity } \\
\hline COPD & 1 & 1 & 1 & 1 \\
\hline Treated diabetes & 0 & 0 & 0 & 0 \\
\hline Insulin-treated diabetes & 0 & 0 & 0 & 0 \\
\hline Stroke & 1 & 1 & 1 & 1 \\
\hline Popliteal disease & 0 & 0 & 0 & 0 \\
\hline Renal disease & 0 & 1 & 1 & 0 \\
\hline $\mathrm{BUN}\left(\mathrm{mg} \cdot \mathrm{dL}^{-1}\right)$ & 14 & 14 & 14 & 14 \\
\hline Cholesterol $\left(\mathrm{mg} \cdot \mathrm{dL}^{-1}\right)$ & 100 & 100 & 100 & 100 \\
\hline Bilirubin $\left(\mathrm{mg} \cdot \mathrm{dL}^{-1}\right)$ & 0.8 & 1 & 1 & 1 \\
\hline Hematocrit $(\%)$ & 40 & 40 & 40 & 40 \\
\hline
\end{tabular}

